OPEN ACCESS

Edited by:

Dominic De Nardo,

Monash University, Australia

Reviewed by:

Michaela Gack

University of Chicago, United States

Surya Pandey,

University of Chicago, United States

*Correspondence:

Hinh Ly

hly@umn.edu

Specialty section

This article was submitted to

Molecular Innate Immunity,

a section of the journal

Frontiers in Immunology

Received: 16 May 2019

Accepted: 25 June 2019

Published: 17 July 2019

Citation:

Brisse $M$ and Ly H (2019) Comparative

Structure and Function Analysis of the

RIG-I-Like Receptors: RIG-I and MDA5. Front. Immunol. 10:1586 doi: 10.3389/fimmu.2019.01586

\section{Comparative Structure and Function Analysis of the RIG-I-Like Receptors: RIG-I and MDA5}

\author{
Morgan Brisse ${ }^{1,2}$ and Hinh Ly ${ }^{2 *}$ \\ ${ }^{1}$ Biochemistry, Molecular Biology, and Biophysics Graduate Program, University of Minnesota, Twin Cities, St. Paul, MN, \\ United States, ${ }^{2}$ Department of Veterinary \& Biomedical Sciences, University of Minnesota, Twin Cities, St. Paul, MN, \\ United States
}

RIG-I (Retinoic acid-inducible gene I) and MDA5 (Melanoma Differentiation-Associated protein 5), collectively known as the RIG-I-like receptors (RLRs), are key protein sensors of the pathogen-associated molecular patterns (PAMPs) in the form of viral double-stranded RNA (dsRNA) motifs to induce expression of type 1 interferons (IFN1) (IFN $\alpha$ and IFN $\beta$ ) and other pro-inflammatory cytokines during the early stage of viral infection. While RIG-I and MDA5 share many genetic, structural and functional similarities, there is increasing evidence that they can have significantly different strategies to recognize different pathogens, PAMPs, and in different host species. This review article discusses the similarities and differences between RIG-I and MDA5 from multiple perspectives, including their structures, evolution and functional relationships with other cellular proteins, their differential mechanisms of distinguishing between host and viral dsRNAs and interactions with host and viral protein factors, and their immunogenic signaling. A comprehensive comparative analysis can help inform future studies of RIG-I and MDA5 in order to fully understand their functions in order to optimize potential therapeutic approaches targeting them.

Keywords: RIG-I, MDA5, PAMP, CARD, interferon, antiviral, inflammation, PRRs

\section{INTRODUCTION}

RIG-I (Retinoic acid-inducible gene I) encoded by the DDX58 gene in the human genome $(1,2)$ and MDA5 (Melanoma Differentiation-Associated protein 5) encoded by the IFIH1 gene $(3,4)$ are known as important protein initiators of earliest immune responses to viral infection. A relatively large body of work has focused on understanding their roles in triggering the same innate immune pathway as they indeed share many similarities at a structural and functional level. However, it is becoming increasingly clear that there are unique differences between RIG-I and MDA5, such as their activation mechanisms and contextual functionalities, that need to be considered in order to fully appreciate their individual function. A comprehensive analysis of multiple aspects of RIG-I and MDA5 from their evolutionary origins and behavior among different species to their structures and molecular signaling will allow for a more nuanced understanding of their functional purposes. 


\section{FUNCTIONAL SIMILARITIES AND DIFFERENCES BETWEEN RIG-I AND MDA5}

The innate immune response is a combination of non-specific defense mechanisms by the host that are critical for early detection and inhibition of pathogen growth before the adaptive immune response has time to produce proper cell-mediated immunity, such as the development of antibodies and cytotoxic T-lymphocyte responses (CTL) against the invading pathogen and/or the pathogen-infected cells (5). Cells of the innate immune arm, such as leukocytes and epithelial cells, are able recognize general components of the microbes (e.g., viruses) that are shared among related microbes. These microbial structures are called pathogen-associated molecular patterns (PAMPs) (e.g., viral dsRNA) that are specifically recognized by the cellular pattern recognition receptors (PRRs) (e.g., RIG-I, MDA5, or Tolllike receptors TLRs) which are then activated (Figure 1). The specific signaling mechanisms of RIG-I and MDA5 activation will be discussed in detail below. Here, the cascade of event leading to IFN1 production is briefly summarized. Upon binding to PAMP (e.g., dsRNA), the activated RIG-I and MDA5 interact with the mitochondrial antiviral signaling proteins (MAVS), which forms a multilayered protein complex contain several different proteins (6-9). The MAVS complex then catalyzes the interaction of inhibitor of nuclear factor kappa-B kinase subunit epsilon (IKK $\varepsilon$ ) and the serine/threonine-protein kinase 1 (TBK1) (10-12), which phosphorylate the transcription factors interferon regulatory factors 3 and 7 (IRF3 and IRF7) (13). Phosphorylated p-IRF7 (14) and -pIRF3 (15) factors then dimerize and translocate into the nucleus, where they activate the expression of the type 1 interferon genes (IFN1: IFN $\alpha$ and IFN $\beta$ ). IFN1 proteins are then exported out of the cell to activate IFN1 signaling cascade by binding to their receptor (the IFN $\alpha / \beta$ receptor or IFNAR) either on the same cells or neighboring cells in an autocrine or paracrine fashion. This results in the production of more IFN1 (in a positive feedback loop) and a variety of interferon-stimulated genes (ISGs), which mediate vasodilation near the site of the pathogen infection and uptake of fluid, recruitment of innate immune cells, such as macrophages, neutrophils, and dendritic cells to the site of the infection that is aided by chemokine gradients to mediate innate immune cell-mediated killing of the infected cells (16).

RIG-I and MDA5 appear to differentially induce IFN1 in response to different viral pathogens (17), with RIG-I generally responding most potently to negative-strand RNA viruses, such as influenza viruses $(18,19)$, bunyaviruses $(20,21)$, filoviruses (22), and rhabdoviruses $(18,23)$ as well as the positive-stranded Japanese encephalitis virus (18), while MDA5 is activated during infection by positive-strand picornaviruses $(18,24,25)$ and arteriviruses $(26,27)$ as well as by hepatitis D virus (28), Kaposi's sarcoma-associated herpesvirus (KSHV) (29). RIG-I and MDA5 may also play a role in recognizing non-viral pathogens, as MDA5 has been found to respond to malaria (30) (Figure 2). Neither are individually critical in reovirus (24) and in dengue virus infection $(24,31)$ but the presence of either in combination with Toll-like receptor 3 (TLR3) is critical to have effective anti-viral repsonses (32). Each serves an additive role during West Nile virus infection (33), which is likely mediated by the production of multiple PAMP species in the infected cells (34). Indeed, RIG-I and MDA5 have also been shown to recognize different sections of the same viral genome due to their differing preferences for RNA binding (35), illustrating how RIG-I and MDA5 can act both independently and synergistically. This has also been shown functionally in viruses where both RIG-I and MDA5 have been found to be essential to induce the necessary levels of IFN $\beta$ signaling for antiviral control against paramyxovirus $(18,36-38)$ and rotavirus infections (39).

While RIG-I and MDA5 participate in the IFN1 signaling pathway (40), it is clear from animal modeling that they might be functionally distinct. While C57BL/6 MDA5 KO mice exhibit no obvious phenotypes (18), C57BL/6 RIG-I KO have high embryonic lethality as they don't live past 3 weeks of birth and experience growth retardation and liver degeneration (18, 41). Furthermore, when RIG-I KO mice are back crossed onto the more genetically flexible 129S1 strain (18), these mice can spontaneously develop colitis symptoms (42). Clinical cases with mutations in RIG-I and MDA5 have distinct autoimmune presentations, with RIG-I mutations being associated with atypical Singleton-Merten Syndrome, while MDA5 mutations have been linked to classical Singleton-Merten Syndrome, Aicardi-Goutières syndrome, Systemic Lupus Erythematosus, Type 1 Diabetes and Graves disease $(43,44)$ (Figure 2). There is growing evidence that overt innate-immune interferon signaling plays a critical role in the development of other forms of autoimmune conditions (45). Taken together, this suggests that RIG-I and MDA5 may differ significantly in their roles during development as well as in responding to different types of viral infection that is partially dependent on the PAMPs that are available in any given context.

There is also increasing evidence that RIG-I and MDA5 have additional distinct molecular functionalities in immune signaling (43). It is well-established that the interferon regulatory factor (IRF) and innate immune NFKB cytokine signaling pathways have many areas of cross-regulation and expression (46). Accordingly, both RIG-I and MDA5 have been shown to activate NFKB signaling during RSV infection, but only RIG-I appears to act upstream of the canonical I $\mathrm{B} \alpha-\mathrm{NF} \kappa \mathrm{B}$ pathway $(47,48)$ (Figure 1). While both are known to activate NFKB mediated expression of IL- 6 and pro-IL- $1 \beta$ through the interaction of CARD9 with BCL10 $(49,50)$, the independence of MDA5 from the I $\mathrm{B} \alpha$ pathway suggests that it influences NFKB signaling in other as yet uncharacterized ways (43). A possible explanation for MDA5's independence from the

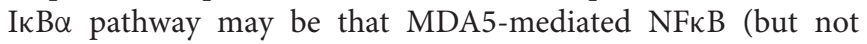
IRF) signaling requires TRIM25, which activates RIG-I by ubiquitination (to be discussed in detail below). This potentially implicates TRIM25 in other mechanisms besides activating RIGI $(51,52)$. RIG-I (but not MDA5) also induces inflammasome assembly-mediated cleavage and maturation of pro- IL-1 $\beta$ by caspase $1(24,34,53)$. Finally, RIG-I has been shown to inhibit RNAi complexes mediated by the endoribonuclease Dicer, which is encoded by the DICER1 gene and cleaves dsRNA and pre-micro RNA into short single-stranded RNA fragments known as small interfering RNA (siRNA) and microRNA 


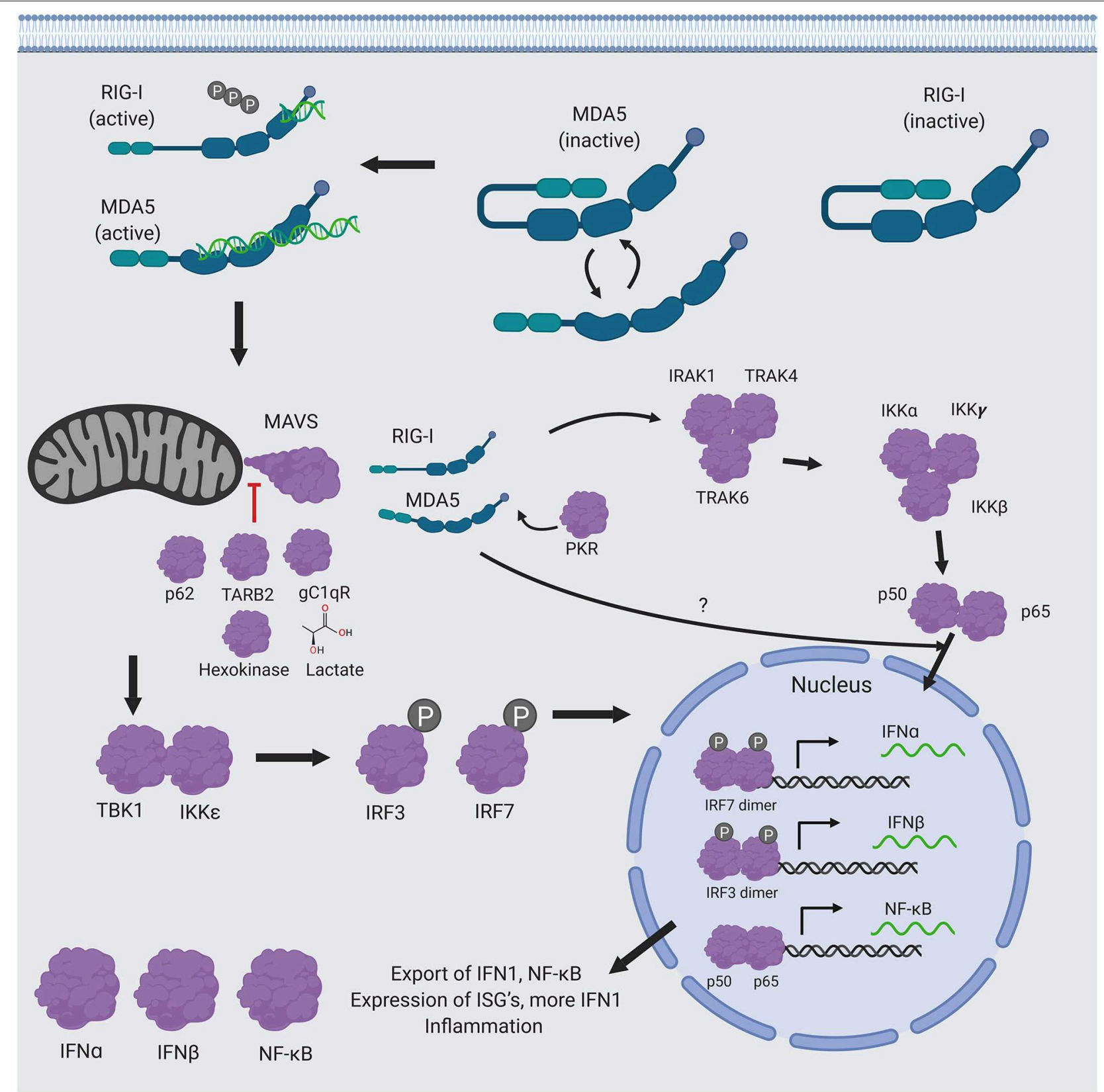

FIGURE 1 | RIG-I/MDA5 signaling pathway RIG-I and MDA5 are first activated by recognition of PAMP dsRNA, which causes them to interact with MAVS. Following the activation of MAVS by RIG-I/MDA5, a molecular cascade involves the interaction of IKKE and TBK1, which is followed by phosphorylation of the transcription factors IRF3 and IRF7, ensure to translocate the phosphorylated p-IRF3 and p-IRF7 into the nucleus, where they dimerize and bind to transcription factor binding sites of the IFN $\alpha$ and IFN $\beta$ genes to activate their transcriptions. Expression and exportation of these genes into the cellular milieu trigger the IFN1 signaling cascade in an autocrine or paracrine fashion to induce expression of hundreds of interferon stimulated genes (ISGs) and inflammatory genes to confer antiviral resistance. RIG-I and MDA5 also activate the NF-кB pathway. RIG-I appears to act upstream of the canonical pathway, which results in the translocation of the two functional NF-kB units (p50 and p65) into the nucleus, while MDA5 appears to affect NF-кB expression independently from this pathway. Figure created using BioRender software.

(54), by interacting with the probable ATP-dependent RNA helicase DHX58 (also known as the Laboratory of Genetics and Physiology 2 LGP2 protein), which inhibits Dicer (55) as well as the Dicer-complex protein TRBP (56). LGP2 has been shown to exhibit conflicting effects on RIG-I and MDA5 signaling (5759), and future studies are needed in order to clarify these regulatory mechanisms.

\section{STRUCTURES OF RIG-I AND MDA5}

RIG-I and MDA5 are expressed in all cell types (60), but are most well-known for their functions inside innate immune cells, such as macrophages, neutrophils, and dendritic cells, as well as in other cells like mucosal epithelial cells. They are classified as ATP-dependent DExD/H box RNA helicases. Their structure 


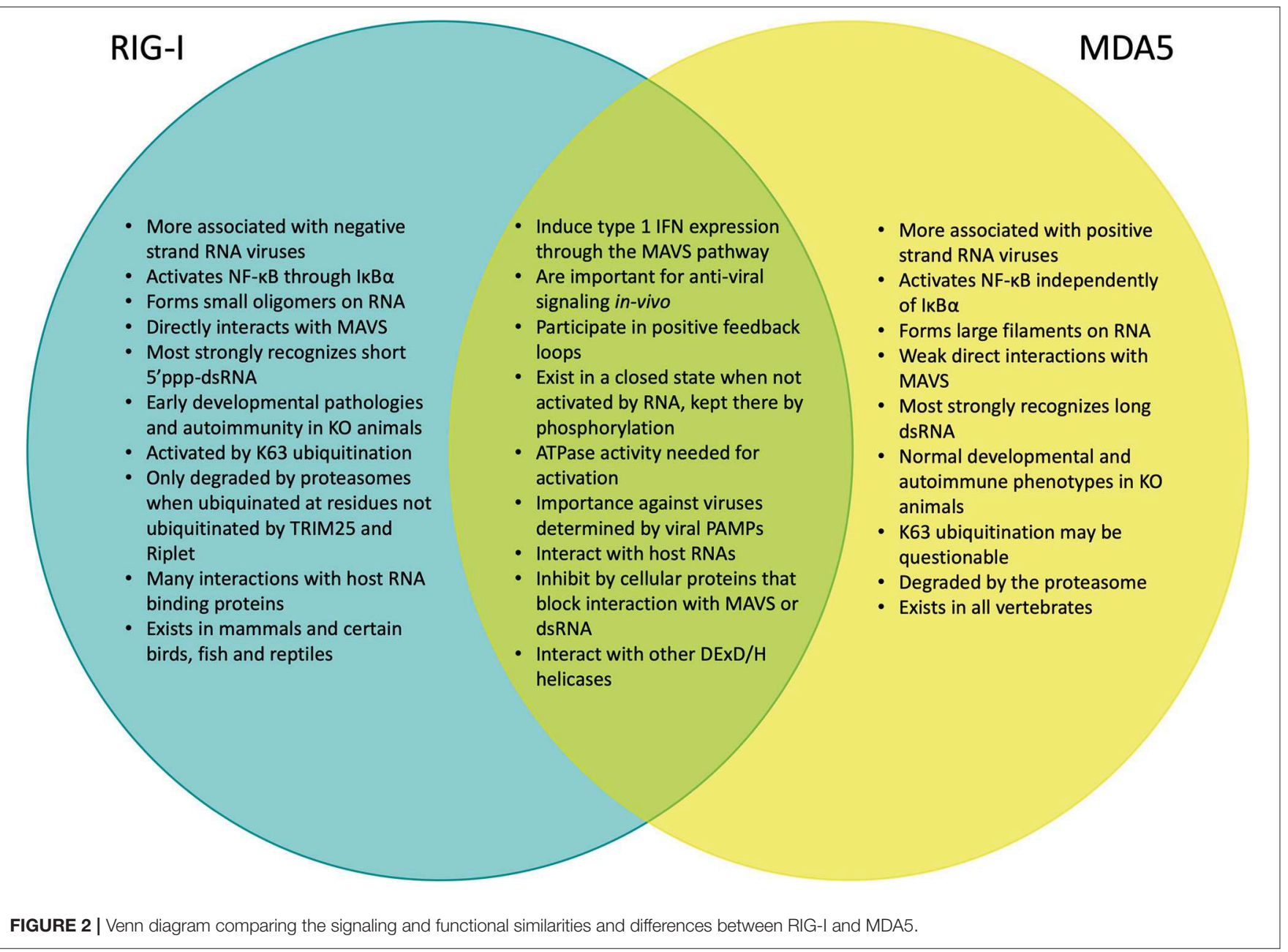

is highly helical and consists of two caspase activating and recruiting domains (CARD) at the $\mathrm{N}$ terminus of $\sim 85$ amino acids each, followed by a flexible hinge region and the helicase domain that consists of the RecA-like Hell and Hel2 domains with an ATP binding and hydrolyzing domain at their interface (Figures 3A,B). In particular, the structure of the ATP binding site distinguishes RIG-I and MDA5 from other helicase proteins, such as Dicer. Unlike other $\mathrm{DExD} / \mathrm{H}$ box helicases where RNA binding catalyzes the ATP binding site to become structurally organized, the ATP binding site in RIG-I and MDA5 remains comparatively open and structurally dynamic following RNA binding. This is aided by the ATP binding site being formed by an interface between the two Hel domains, which are relatively far apart (64).

These structural features are connected by another flexible hinge region to the unique and predominantly $\beta$-sheet $C$ terminal domain (CTD), which recognizes and binds to RNA (65). The CTD in RIG-I and MDA5 contains a zinc binding domain that is related to those of the GDP/GTP exchange factors (66). Each protein also contains a positively charged groove within this domain that recognizes dsRNA and this groove is structurally unique in each protein, potentially explaining their different
RNA binding preferences (66). RIG-I primarily recognizes short double-stranded RNA with $5^{\prime}$ triphosphate groups (67-75), while MDA5 primarily recognizes long double-stranded RNA (76-79) (to be discussed in detail below.) It is notable in this regard that the Hel-CTD motifs adopt different orientations relative to dsRNA in RIG-I and MDA5. Specifically, the RIG-I Hel-CTD domain is tilted relative to dsRNA with the CTD interacting with the $5^{\prime}$ and $3^{\prime}$ ends of the dsRNA (61), whereas the MDA5 HelCTD domain runs parallel to the RNA strand (Figures 3C,D).

\section{ACTIVATION OF RIG-I AND MDA5 BY POST-TRANSLATIONAL MODIFICATIONS}

The series of steps required for RIG-I and MDA5 activation have been described in depth elsewhere (80-84). Briefly summarized, these proteins endogenously exist in the cytoplasm of the cell in a phosphorylated and inactivated conformation when they are not activated by PAMP (dsRNA) (85-87) (Figures 4A,F). Phosphorylation is mediated at the $\mathrm{N}$ terminal CARD domains (S8 and T170) of RIG-I by PKC- $\alpha / \beta(88,89)$ and at the C terminal RNA interaction domain (S854, S855, and T770) by 


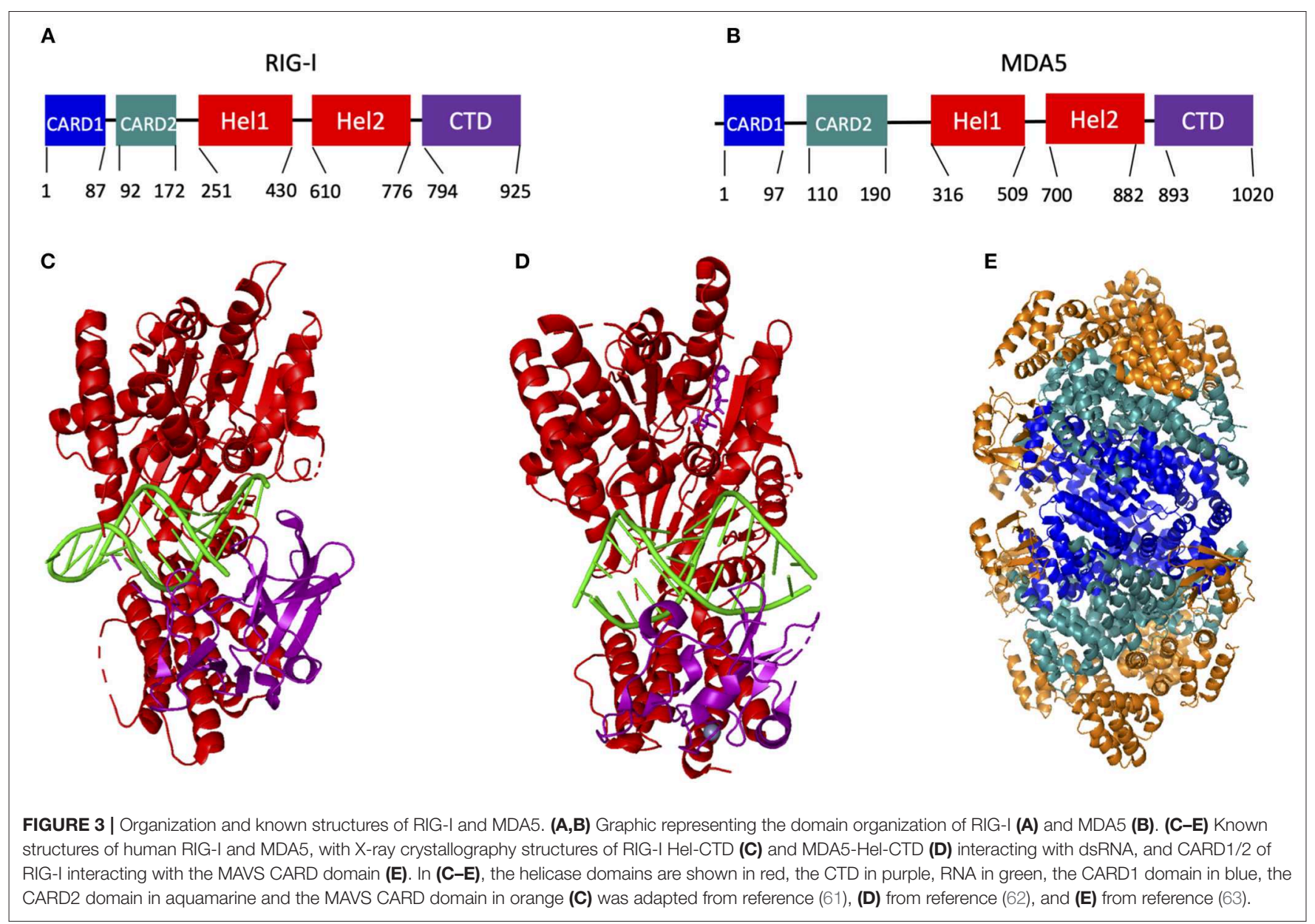

CK $\beta$ (90). On the other hand, MDA5 is phosphorylated at $\mathrm{S} 828$ by RIOK3 (91) as well as by other yet unknown kinases (92, 93). RIG-I is also acetylated at K909 in its C terminal domain that requires deacetylation by HDAC6 to be able to recognize RNA in its activated form (94). Upon recognition of PAMP (dsRNA), RIG-I unfolds into an open and activated state that is mediated by the flexible hinge regions between the CARD domains and the helicase domain, and between the helicase and the $C$ terminal domain $(64,87,95-98)$ (Figure 4B). On the contrary, there is evidence to suggest that MDA5 has a more dynamic structure (99). Unlike a model of RIG-I activation described above, MDA5 exists in a conformational equilibrium between close and open forms, with close forms favored in the dsRNA unliganded state. While not yet formally demonstrated, it is possible that MDA5 may be inhibited in the absence of the dsRNA ligand by its structural dynamics, which may prevent strong protein-protein interactions (Figure 4F). However, upon binding to dsRNA ligand, MDA5 adopts an open and activated form, which is perhaps more conducive for protein-protein interactions (Figures 4G,H).

Once the $\mathrm{C}$ terminal domains have been de-phosphorylated, the E3 ubiquitin ligase Riplet attaches ubiquitin peptides onto the $\mathrm{C}$ terminal domain of RIG-I at residues K849 and K851
$(100,101)$. It was previously shown that ubiquitination by Riplet was necessary for opening RIG-I and for ubiquitination of the CARD domain (102). However, in-situ studies found that dsRNA was sufficient to weaken the interaction between purified RIGI C terminal domain and RIG-I CARD domains (86) and that dsRNA was necessary for Riplet ubiquitination (103), calling into question the sequential order for RIG-I activation (Figure 4C). Following de-phosphorylation of the CARD domain by the phosphatase PP1- $\alpha / \gamma$ (92), this domain is polyubiquinated at K172 by the E3 TRIM25 ubiquitin ligase (104), which itself is activated by Caspase 12 (105) (Figure 4D). TRIM25 interacting with RIG-I may also be mediated by their mutual interactions with certain host long non-coding RNA (lncRNA), which occurs outside of the dsRNA recognizing domain in the CTD of RIG-I (106).

A recent study showed that Riplet rather than TRIM25 was primarily responsible for ubiquitinating and activating RIG-I (103). However, there are several factors to take into consideration with this study. These recent results were obtained using KO 293T and mouse embryonic fibroblast (MEF) cells and that it was not clear whether K63 ubiquitination occurred at other known lysine sites in RIG-I. The question remains whether Riplet can ubiquitinate other lysine residues 


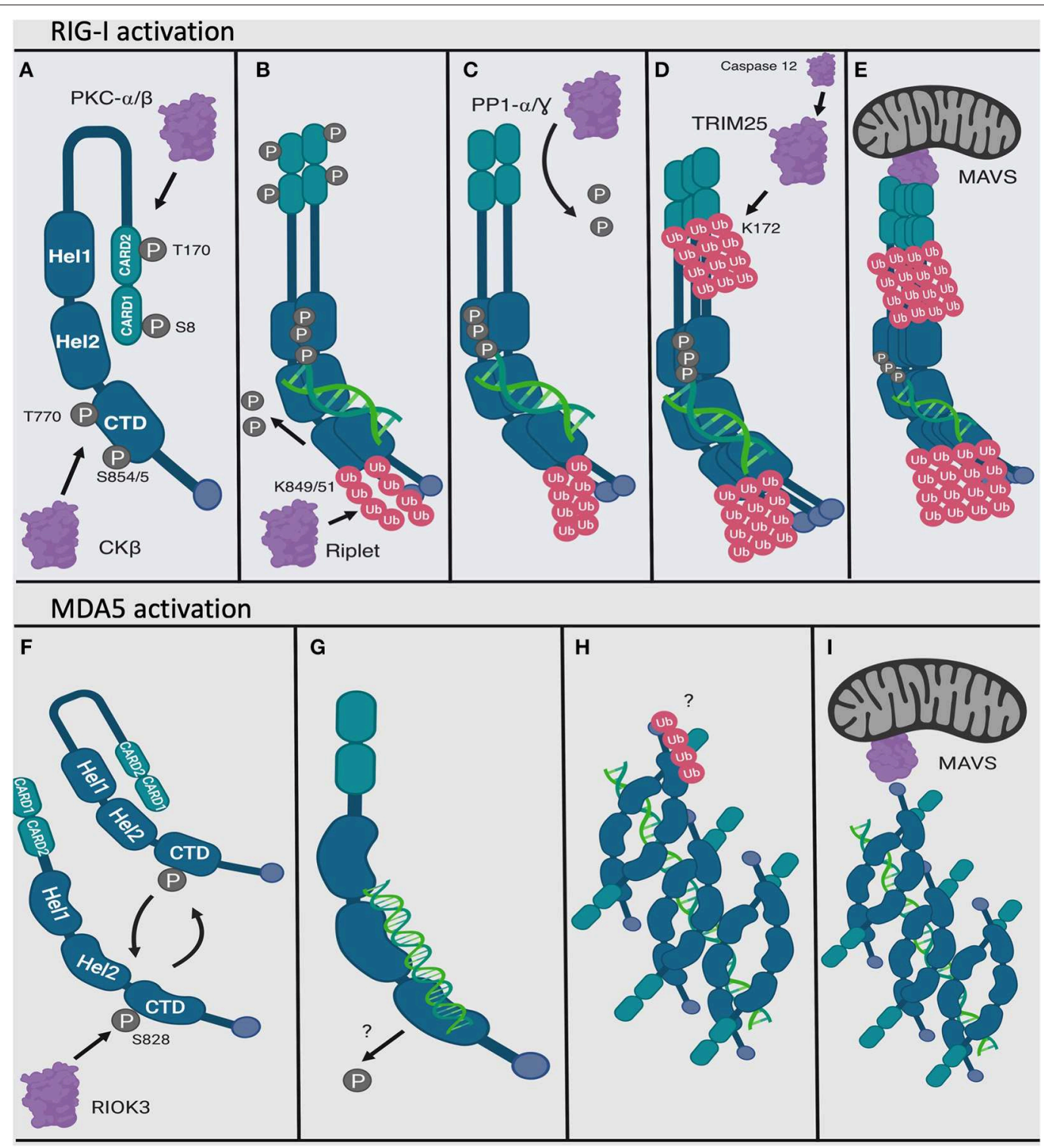

FIGURE 4 | Activation mechanisms of RIG-I and MDA5. RIG-I and MDA5 are activated by interacting with viral dsRNA at the C terminal domain. In their endogenous and inactivated state, RIG-I and MDA5 are phosphorylated at their N and C terminal domains (A,F). MDA5 may exist between open and close forms in its inactivated state (F). Upon recognizing PAMP dsRNA, the C terminal domain becomes dephosphorylated and ubiquitinated for RIG-I and dephosphorylated for MDA5 (B,G). RIG-I also dimerizes (B). Next, RIG-I oligomerizes (D) and MDA5 forms longer filaments on dsRNA (H), and the N terminal CARD domains of RIG-I becomes dephosphorylated (C) then ubiquitinated (D). Finally, the CARD domain of the RIG-I oligomers interacts with the mitochondrial protein MAVS (E), and the MDA5 dsRNA filaments also activate MDA5 (though it has a weaker CARD-CARD interaction with MAVS) (I). Figure created using BioRender software.

in the absence of TRIM25. Additionally, in-situ experiments comparing RIG-I ubiquitination by Riplet and TRIM25 utilized an E2 enzyme (103) that had been found to be specific for Riplet (107). While the E2 that utilizes TRIM25 has not yet been identified, TRIM25 has been shown to ubiquitinate RIG-I in-situ when a general mixture of E2 proteins was used (108). The protein levels of TRIM25 may also have to be at a certain level in order for it to productively ubiquitinate RIG-I, as the ubiquitin protease USP15 deubiquitinates TRIM25 at later time points in viral infection (109).
Finally, TRIM25 has been found to be essential for RIGI activation and IFN signaling in-vitro and in-vivo. For the former, siRNA-mediated knock-down $(110,111)$, cellular knockout (112) and inhibition by viral protein (109, 113-116) conditions for TRIM25 in multiple cell types have been shown to change RIG-I cellular localization (110) and to negatively affect RIG-I K63 ubiquitination, association with MAVS and IFN signaling [when the constitutively active RIG-I CARD domain was overexpressed $(109,112-116)$ or during viral infection (109, $111,114)]$. Viral inhibition of TRIM25 may even be a source of a positive selection during the evolution of certain viruses, 
as NS1 IAV proteins have been found to interact with species specific TRIM25 (114). For the latter, MEFs from TRIM25 KO mice have significantly downregulated IFN1 production upon viral infection (113) and KO mice for NLRP12, which is a competitive interactor with TRIM25 to RIG-I, show increased interferon production and more resistance to viral infection (117). The known contributions of TRIM 25 to innate immunity have recently been summarized elsewhere (52).

It is clear that both Riplet and TRIM25 can mediate K63linked polyubiquitination. However, it has also been found that in-situ incubation of purified RIG-I CARD domains with ubiquitin can be activated by free and unlinked K63 polyubiquitin chains (118), calling into question whether TRIM25 only attaches K63-linked ubiquitin motifs to RIG-ICARD or if it also catalyzes the formation of unlinked K63 polyubiquitination chains (119). A possible explanation for these differing results is that RIG-I has been shown to be covalently K63 ubiquitinated by TRIM 25 when analyzed by mass spectrometry from cells (104), while experiments that demonstrate non-covalent K63 ubiquitination are those involve primarily interactions with purified proteins.

It has also been recently found that RIG-I is K63 ubiquitinated at K164 and that it may be functionally redundant to K172 $(120,121)$, with their ubiquitination possibly upregulating the K63 ubiquitination of the other 6 lysine residues in RIG-I (121). However, it is unknown whether TRIM25 ubiquitinates K164 or any of the other RIG-I lysine residues. Notably, these additional lysine residues in the CARD and C terminal domains of RIG-I and MDA5 are known to be K27 and K48 ubiquitinated [which are associated with degradation of RIG-I $(122,123)$ and MDA5 (123)], but the four listed above appear to be the essential residues for activation of RIG-I $(122,124)$.

The presence of K63 ubiquitin modifications on MDA5 is more controversial. Independent studies have found that MDA5 is $(125,126)$ or is not $(126) \mathrm{K} 63$ polyubiquitinated. It has also been independently found that TRIM25 does not affect ubiquitination of MDA5 (without distinguishing between K63 and K48 polyubiquitination) (104) and for TRIM25 to increase K63 ubiquitination (125), the only apparent difference in the experimental models being the usage of $\operatorname{HEK} 293 \mathrm{~T}(104,126)$ vs. HEK293 (125) cells. TRIM65 has also been recently found to be essential for MDA5 activation by K63 polyubiquitination at K743 (127). It is clear that additional studies are needed in order to clarify the ubiquitination mechanisms of MDA5.

\section{OLIGOMERIZATION AND FILAMENTATION TO ACTIVATE RIG-I AND MDA5 FUNCTIONS}

Upon binding to PAMP (dsRNA), RIG-I oligomerizes with other RIG-I/dsRNA complexes to form helical oligomers (128) in a 2:2 complex using the purified RIG-I protein (87), where the activating ubiquitin motifs serve as a scaffold to link the oligomers together (118). These oligomers have been found to be necessary under normal conditions to activate RIG-I. This may be due to the helical structure of the RIG-I oligomers closely matching those formed by MAVS (63), which is known to form filaments in-vitro $(129,130)$ mediated by its own CARD domains $(131,132)$. A structural model of MAVS activation by RIG-I has been proposed of stacking MAVS CARD domains on top of RIG-I CARD domains to extend the RIG-I helix (133).

The minimum length of dsRNA found to activate RIG-I is 13 base pairs, which is equivalent to the minimum length to facilitate the formation of a 2-RIG-I/dsRNA dimer (75). That being said, shorter ( $\sim 10$ bp) 5'ppp stem loop dsRNA complexes that have previously been used to obtain X-ray crystallographic structures of RIG-I interacting with dsRNA (61, 134, 135) (Figure 3C) can also activate IFN $\beta$ signaling in cells $(135,136)$ and in mice (136). Furthermore, A549 cells that were transfected with RIG-I plasmid $6 \mathrm{~h}$ prior to RNA transfection had a minimum dsRNA length of only 8-10 bp required for activation (75). This indicates that RIG-I oligomerization may not be necessary for activation of the IFN $\beta$ pathway under some experimental conditions, which need to be further investigated.

MDA5 has also been shown to oligomerize to form long RNAassociated filaments in vitro $(62,137,138)$ (Figures 3D, 4H), which may be aided by chaperone proteins (139). Given that the K743 residue found to have been ubiquitinated by TRIM65 (127) is located on the surface of Hel2, it is possible that K63 ubiquitin residues may also help stabilize MDA5-dsRNA filaments (140). However, MDA5 also spontaneously forms filaments and induce MAVS to form filaments independently of ubiquitin in-situ. It is also thought that the formation of longer filaments by MDA5 may be mediated by a longer linkage region between CARD2 and Hell than in RIG-I by 50 amino acids (the length of which is wellconserved across species), allowing for the association of more CARD domains in an oligomer (133).

The formation of longer filaments by RIG-I has been more controversial, giving rise to two alternate models of RIG-I activation: formation of individual single unit of RIGI with short dsRNA monomers (leaving a free dsRNA end, such as a hairpin loop), which then oligomerizes via CARD tetramerization that is linked by their ubiquitin chains, or filamentation on longer dsRNA. Like MDA5, RIG-I can form filaments in-situ independent of ubiquitin $(141,142)$ and induces MAVS to also form filaments (142), and MAVS is known to form filaments in-vitro $(129,130)$ mediated by its own CARD domains $(131,132)$. However, RIG-I filamentation on an RNA template (forming "beads on a string") as opposed to smallerscale oligomerization hasn't yet been shown to occur in-vitro. Part of the reasons for the suggestion that RIG-I was strongly activated by shorter dsRNA was based the comparison on mass equivalents of RNA species as there were less $5^{\prime}$ triphosphorylated ends for longer dsRNAs with greater mass than shorter dsRNAs with more $5^{\prime}$ triphosphorylated ends (76). However, when RNA species were normalized by molar equivalence, dsRNA length appeared to be positively correlated with RIG-I signaling (141143), which became insignificant at around $500 \mathrm{bp}(141,143)$. It is significantly shorter than the length of dsRNA that activates MDA5, which forms filaments on 2,000 bp dsRNA (137). The kinetics of RIG-I and MDA5 interacting with dsRNA (which will be discussed in detail below) might possibly explain the decrease in dsRNA length efficiency to activate RIG-I as compared to 
MDA5, as RIG-I seems to first recognize the 5'ppp end before sliding down the length of the dsRNA (144), whereas MDA5 dynamically associates and disassociates along the length of long dsRNA (137). Meanwhile, it is still unclear whether RIG-I can preferentially be activated by longer dsRNA independently of its unknown ability to form filaments in-vitro (145).

\section{MODES OF RLR-MAVS INTERACTION AND RLR DOWNSTREAM SIGNALING}

Once fully activated and oligomerized, the RIG-I CARD domain can then interact with MAVS (146-149) (Figures 4E,I), which is part of a protein complex containing a variety of other cellular proteins (6-9). While the MDA5 CARD domain has much weaker direct association with MAVS than the RIG-I CARD domain, it is sufficient to lead to its activation and potentiates activation of MAVS by RIG-I (146), the mechanisms of which have yet to be determined. The activated MAVS complex then initiates a molecular cascade which eventually results in expression of IFN1 (150) (Figure 2).

Interestingly, full length RIG-I, when overexpressed, has been found to associate with MAVS in the absence of activating dsRNA and the interaction can be ablated by phosphorylation at S8 and T170 (87), suggesting that the CARD phosphorylation sites function at least in part to prevent association of the inactive form of RIG-I with MAVS. Furthermore, the crystal structure of the interaction between the RIG-I CARD and MAVS CARD domains shows the RIG-I CARD2 domain (92-173) interacting with MAVS CARD domains on the outside of the tetramer and the RIG-I CARD1 (1-87) domain facing toward the center of the tetramer (63) (Figure 3E). NMR solution structures of RIG-I CARD2 also shows that T170 (which is required for dephosphorylation by $\mathrm{PP} 1-\alpha / \gamma)$ is largely buried within the CARD2 domain in a section that would be in closer contact with the helicase domains, suggesting that dephosphorylation of T170 affects an interaction domain between CARD2 and the C terminus (151). Furthermore, NMR of a C terminal construct of RIG-I with the CARD2 domain shows stable interactions of CARD2 and the C terminal domain (151). What all this may mean is that, while the CARD1 domain of RIG-I is somewhat exposed in its inactivated form and therefore can be shown to interact with MAVS, full exposure and engagement of both RIG-I CARD domains (CARD1 and CARD2) with the CARD domain of MAVS is necessary in order to induce IFN1 signaling. The CARD domains of RIG-I also appear to be generally structurally stable, as electron microscopic structures have been obtained of the full length RIG-I bound to blunt-ended dsRNA showing both CARD domains exposed (87). On the contrary, the CARD domains of MDA5 may be comparatively more flexible than those of RIG-I in order to mediate long MDA5-dsRNA filament formation (99).

The activated MAVS complex induces association of the inhibitor of nuclear factor kappa-B kinase subunit epsilon (IKK $\varepsilon$ ) and the serine/threonine-protein kinase 1 (TBK1) (10-12), which collectively phosphorylate the interferon regulatory factors 3 and 7 (IRF3 and IRF7) (13) (Figure 1). IKK $\varepsilon$ and TBK1 also interact with a number of other co-factors $(152,153)$, such as the DEADbox helicase 3 (DDX3) (154). The activated p-IRF3 (15) and p-IRF7 (14) then translocate into the nucleus and dimerize, where they then act as the primary transcription factors for IFN $\alpha$ and IFN $\beta$, respectively. Existing evidence suggests that IFN $\alpha$ is more primarily produced in the earliest time points following RIG-I/MDA5 activation, while IFN $\beta$ is produced later and is responsible for more robust anti-viral control throughout the innate immune response period (155). There is also a distinction between innate immune cell types for IFN1 production, as cells like fibroblasts and conventional dendritic cells produce IFN $\alpha$ and IFN $\beta(41,156)$, while neutrophils only produce IFN $\beta$ (157) and plasmacytoid dendritic cells only produce IFN $\alpha$ primarily through the TLR signaling pathways $(41,158)$. Signaling through RIG-I is also known to be essential for the process of TLRmediated phagocytosis by macrophages (159).

Interferons are then secreted out of the cell, where they bind to their own receptor (IFNAR) and activate the Janus kinase/Signal Transducer and Activator of Transcription proteins (JAK/STAT) signaling pathways, which result in a positive feedback signaling loop to further increase RIG-I/MDA5 expression and activation (160) and IFN1 production $(161,162)$. Expression levels of RIGI and MDA5 have consistently been found to be upregulated downstream of type I $(163,164)$ and type II $(165,166)$ IFN signals. MDA5 upregulation has additionally been found to occur independently of cytokine expression at least during picornavirus infection (167).

\section{SPECIFIC RNA FEATURES RECOGNIZED BY RIG-I AND MDA5}

One of the most obvious distinctions between RIG-I and MDA5 is in the RNA species to which they bind for activation (Figures 1, 5). RIG-I has the highest affinity for short dsRNA that is tri-phosphorylated at the $5^{\prime}$ end (67-75), with RIG-I having been found to directly interact with the $5^{\prime}$ tri-phosphate group of the dsRNA $(71,73)$. While RIG-I can bind to ss-5' tri-phosphorylated RNA (69), RIG-I cannot be activated by it $(69,168,169)$, likely due to a conformational need to recognize double-stranded RNA. As a result, RIG-I is greatly attenuated by a $5^{\prime}$ overhang as well as those with a $3^{\prime}$ overhanging the $5^{\prime}$ tri-phosphate end (170). In fact, a single unpaired $5^{\prime}$ triphosphorylated nucleotide is sufficient to competitively inhibit RIG-I, which has been exploited by RNA viruses to evade RIGI recognition and IFN1 signaling (171). The unique preference of RIG-I for $5^{\prime}$ tri-phosphorylated RNA can be explained by the specific orientation that the RIG-I C terminus adopts when directly interacting with the $5^{\prime}$ tri-phosphate group of the $5^{\prime}$ tri-phosphorylated dsRNA $(71,73)$ as compared to unphosphorylated blunt-ended dsRNA (172).

The minimally required and exclusionary features of the $5^{\prime}$ and $3^{\prime}$ dsRNA ends for RIG-I activation have proven to be complex. Certain studies suggest that a $5^{\prime}$ diphosphate group is the minimum feature required for RIG-I binding and activation, with $5^{\prime}$ monophosphate dsRNA failing to productively activate RIG-I as compared to $5^{\prime}$ di and tri-phosphate dsRNA (173). 

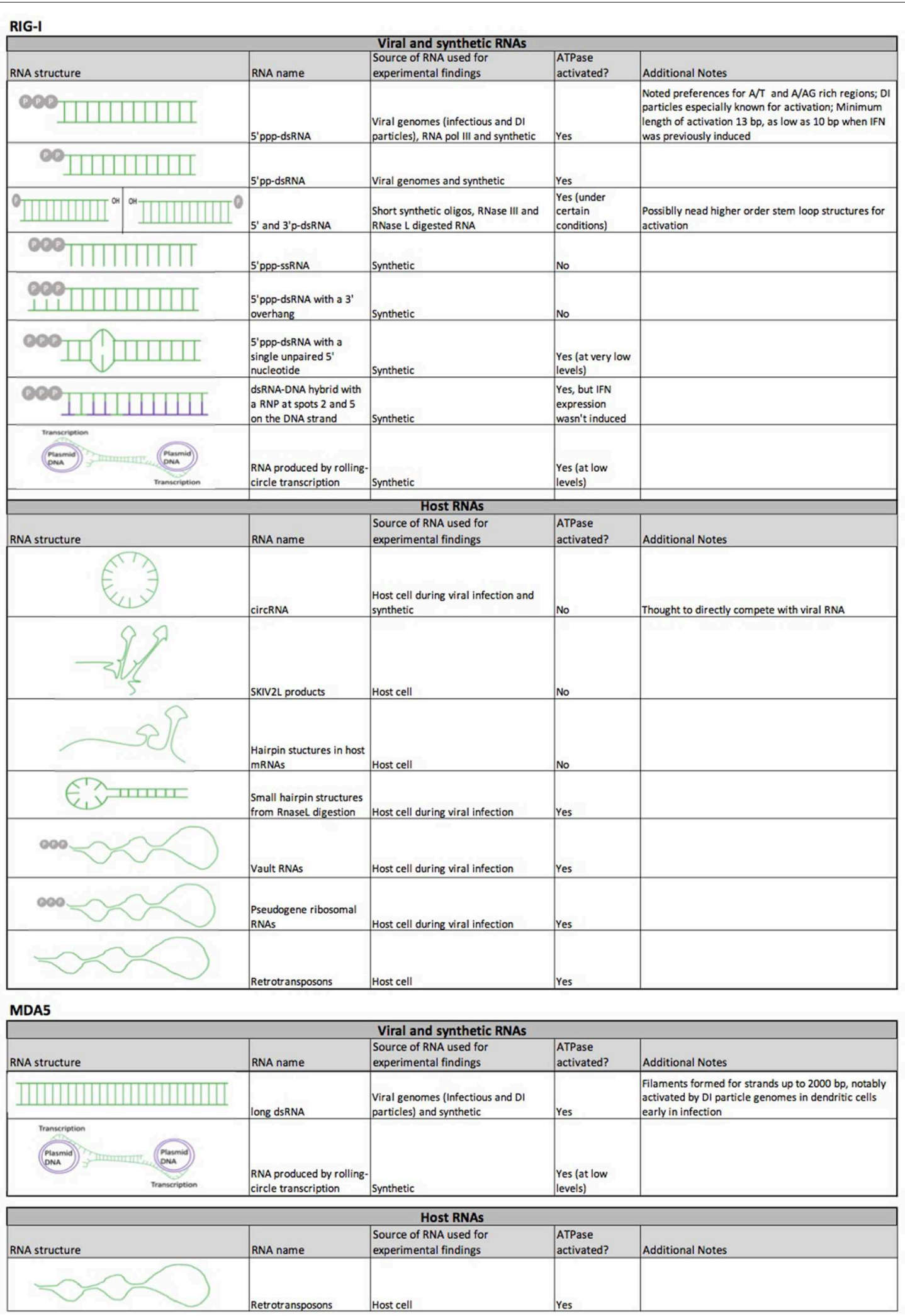

FIGURE 5 | RNA species that interact with RIG-I and MDA5. Table summarizes the general structural features of RNA species, their source during experimental studies and their ability to activate the ATPase functions of RIG-I and MDA5. RNA constructs are shown in green, and DNA constructs in purple. 
Additionally, RIG-I poorly distinguishes between dsRNAs with either $5^{\prime}$ tri-phosphate and $5^{\prime}$ diphosphate group. When the free energies of each interaction are calculated, the affinity for $5^{\prime}$ triphosphate being lowered by disassociation of magnesium from the RIG-I/dsRNA complex. Both are significantly more favorable for binding RIG-I monophosphate dsRNA (174). This similarity in affinity appears to be important in the context of infection with viruses that produce $5^{\prime}$ diphosphate RNAs, such as reoviruses (173). Likewise, the difference of energic binding between monophosphate dsRNA and bi- and triphosphate dsRNAs is likely important for distinction between self (host) and non-self (foreign) RNA, the mechanisms of which will be discussed in detail below. The ATP hydrolysis functions of RIG-I have been shown to drive rapid disassociation from certain RNA features, such as $5^{\prime}$ monophosphate dsRNA $(174,175)$ and $5^{\prime} \mathrm{OH}$ RNA $(144,176)$, which is particularly important for $5^{\prime}$ monophosphate dsRNA because it is found in mRNA after decapping during the mRNA degradation process (177).

On the other hand, other studies have shown that RIG-I can interact with monophosphate dsRNA to a certain degree, as has been found to be the case for short synthetic dsRNA with a $5^{\prime}$ and $3^{\prime}$ monophosphate group (69), poly(I:C) digested with RNase III (76) [which generates $5^{\prime}$ mono-phosphate/3'-OH dsRNA (178)] and HCV RNA (179) and mitochondrial RNA [in the p53 deficient mice (180)] digested with RNase L [which produces $5^{\prime} \mathrm{OH}$ and $3^{\prime}$ mono-phosphate dsRNA at subnanomolar levels (181), as has been found to be the case for HCV RNA (179).] It appears that the $5^{\prime}$ monophosphate is the determinate feature for RIG-I activation independently of the $5^{\prime}$ or $3^{\prime} \mathrm{OH}$ group in all these cases. A possible explanation for the discrepancy between the studies was that higher order RNA structures might compensate for the less optimal $5^{\prime}$ and $3^{\prime}$ ends, as monophosphate dsRNA that did not contain stem-loop structures did not activate RIG-I and RNA regions repetitive in certain nucleotides had been found to be critical for RIG-I activation (179). Future studies are required to further characterize the behavior of RIG-I with these RNA species.

As previously mentioned, MDA5 preferentially associates with long dsRNA (76-79). The crystal structure and molecular modeling of MDA5/dsRNA complex suggest that it can recognize the entire first turn of the blunt-ended dsRNA (182) in a similar way as LGP2 can (183). Like RIG-I and MDA5, LGP2 belongs to the ATP-dependent DExD/H box RNA helicases (184), which is structurally similar to RIG-I and MDA5 but lacks the CARD domains at the $\mathrm{N}$ terminus (185). MDA5 has also been found to be activated by the digested products of RNase L specifically from parainfluenza virus (186).

The presence of certain repetitive RNA elements appears to be another contributing factor in determining interaction of RNA with RIG-I and MDA5, which has recently been described in detail elsewhere (187). While RIG-I and MDA5 are mostly implicated in the immune response to RNA viruses, it has also been found to be activated by $5^{\prime}$ tri-phosphorylated dsRNA intermediates generated by cellular RNA polymerase III from AT-rich DNA sequences (188) and during infection with Epstein-Barr virus (a DNA virus) (189). RIG-I has additional binding preferences for certain nucleotide motifs, such as uridine-rich $5^{\prime}$ tri-phosphorylated hairpin RNA (190), synthetic AU- rich hairpins (191) and those naturally found in the genomes of Sendai virus defective-interfering (DI) particles (192), measles (193), Influenza A virus (IAV) (194) and in KSHV RNA transcripts (195), and poly (U/UC) regions (196) and poly (A/AG) regions (197) in the antisense Hepatitis C virus (HCV) genome. It is of particular interest that the poly (A/AG) HCV regions are located significantly downstream of the 5 triphosphate group (197), thus potentially implicating other parts of RIG-I (e.g., helicase domain) as potential RNA interacting domains. Repetitive RNA elements may also be important in allowing for interaction of inhibitory RNAs that do not have $5^{\prime}$ or $3^{\prime}$ features needed for full activation of RIG-I, as has been shown to be the case with GA-rich regions in circular longnon-coding RNA lnc-Lsm3b (198). These specific interactions explain their primary role as anti-viral receptors, as these viral motifs are mostly not found in cellular RNAs (199).

RIG-I and MDA5 have been particularly implicated in their response to RNA genomes of viral defective interfering (DI) particles, as these defective viral genomes (DVGs) have originally been found to induce interferon signaling (150). DI particles are produced by many viruses during infection, and while they are similar in many regards to standard viral particles, such as in appearance and composition, they cannot productively infect cells (200). This is largely thought to be due to the presence of large and deleterious deletions in the DVG of DI particles (201). Some DVG RNAs have also been noted to have "copy-back" motifs in which one end of the genome can base pair with an inverted copy at the opposite end of the genome, which may be due to stalled and aberrant replication $(202,203)$.

Copy-back RNA motifs specifically seem to be important for RLR activation in that they tend to contain hairpin motifs and 5 ' tri-phosphate groups, as has been found for Sendai (204206), measles $(35,207)$, and chikungunya (35) DVG RNAs in activating RIG-I. In the case of IAV, DVG RNAs might even be more potent activators of RIG-I than the full-length viral genome. Cells that were blocked from viral protein synthesis experienced RIG-I mediated IFN1 expression when infected with IAV stocks grown in chicken embryonic eggs (which produced higher relative quantities of DI particles with DVG RNAs) but not with IAV grown in cell culture, indicating that RIG-I activation by the genomes from primarily non-DI IAV particles may require active viral RNA synthesis (208). A potential explanation to this observation is that RIG-I appears to be activated by the full viral genome via its panhandle structure, the affinity of which is lowered by the presence of mismatched and unpaired nucleotides in this region of the viral genome that is conserved across influenza virus strains (209). However, the overall panhandle structure is conserved between DVGs (205) and the full length viral genome (209), and deletions within DVGs are monogenic and internal (210). The specific molecular mechanisms of enhanced RIG-I signaling by IAV DVGs have yet to be elucidated, although the level of exposure of the panhandle may play a role. While the full extent of MDA5 interacting with DI RNA is currently unknown, MDA5 appears to be more predominantly activated by DVG RNA than RIG-I specifically 
in dendritic cells early in the viral infection cycle (211), which may be a contributor toward the phenomenon of DI particles enhancing dendritic cell maturation (212).

The comparative abilities for DI particles vs. infectious virions to activate RIG-I and MDA5 have important implications for understanding viral pathogenesis and for vaccine development. There is a burgeoning interest in this regard, especially in populations which are typically more challenging to achieve successful preventative vaccination, such as elderly populations with IAV vaccination (213). Elderly populations in general do not develop as strong of memory immune responses to vaccines as their younger counterparts (214-217) and have been found to have decreased RIG-I mediated IFN1 signaling (218). Correspondingly, the influenza vaccine has been shown to decrease in effectiveness in older populations as the influenza season progresses (219). A DI-vaccine that strongly activates innate immune cells and increases the adaptive immune response could therefore potentially boost the immune responses to vaccines in more vulnerable populations. Additionally, DI particles have shown to be an important contributor of viral persistence $(200,220,221)$. This raises the question of whether a viral infection may alternate between producing primarily infectious virions which eventually activates the innate immune response and producing primarily DI particles which requires less cellular activity but may initiate an even stronger innate immune response (222-224). Taken altogether, DI particles provide yet another layer of distinction between RIG-I and MDA5 in terms of how each recognizes different species of dsRNA.

\section{DISTINCTION OF SELF (HOST) AND NON-SELF (FOREIGN) RNAS BY RIG-I AND MDA5}

The preference for specific RNA species by RIG-I and MDA5 allow for them to distinguish between viral RNA and host RNA in most circumstances (225), although the specific mechanisms of distinction are not as clear for MDA5 as for RIG-I. Studies from clinical cases of MDA5 mutations provide contradictory models, with certain mutations found in Aicardi-Goutières syndrome (AGS) increasing MDA5 avidity for self RNA (226) with Alu retroelements found to be significantly enriched for interaction with AGS MDA5 mutations (227). The modification of dsRNA by host cells may be a primary inhibitor of MDA5 activation by host RNA as knockout of adenosine deaminase (ADAR1), which weakens dsRNA structures, allows wild-type MDA5 to be activated by Alu retroelements (227). However, other MDA5 mutations decrease affinity for known MDA5 ligands and ATPase activity, yet still demonstrate increased IFN $\beta$ expression $(228,229)$.

For RIG-I, a highly conserved residue in the C-terminal RNA binding pocket (H830) has been found to sterically exclude canonical self-RNA by the means of the $\mathrm{N}_{1}-2^{\prime} \mathrm{O}$-methyl self-RNA motif, also known as Cap1 RNA $(61,230)$. This results in a low binding affinity of RIG-I to cellular Cap1 RNA and decreased ATPase activity as compared to PAMP
(dsRNA) (61, 231). Flaviviruses take advantage of this precise discrimination by encoding a viral $2^{\prime}$-O-methyltransferase capable of $\mathrm{N}_{1}-2^{\prime} \mathrm{O}$-methylating its positive-strand RNA genome in order to evade RIG-I recognition and IFN1 activation (230). Conversely, the mutations E373A and $\mathrm{C} 268 \mathrm{~F}$ found in the RIG-I protein in patients with auto-immune disorder SingletonMerten syndrome confer the ability of the protein to recognize Cap1 RNA and become activated by ATP dependent and independent mechanisms, respectively (232). Furthermore, the E373Q mutation of RIG-I, which was designed to constitutively bind ATP, was found to increase the affinity of RIG-I with ribosomal RNA (233). It is noteworthy that host RNA contains additional internal RNA modifications and non-Watson-Crick base pairing which can inhibit activation of the other known dsRNA-sensing protein, the interferon-induced double-stranded RNA-activated protein kinase (PKR) (234), and it is known that synthetic $5^{\prime}$ triphosphorylated RNA containing pseudouridine, 2-thiouridine or 2'-O-methylated uridine has significantly decreased ability to activate RIG-I (67), which has been demonstrated to occur by preventing RIG-I filament formation in-situ (142). N-6-methyladenosine (m6A) nucleotides, which are well-known nucleotide modifications among viruses (235), have also been found to ablate dsRNA binding to RIG-I (236).

It has been demonstrated that certain RNA-DNA hybrid constructs with ribonucleotides at positions 2 and 5 of the DNA strand can bind to RIG-I and activate its ATPase activity (75). ATPase activity is necessary for full activation of RIG-I and expression of $\operatorname{IFN} \beta(75,237)$, so the minimum requirement of a motif not found in host RNA for ATPase activity has significant implications for the distinction between self and non-self RNAs. Expanding on this observation, exogenous ATPase activity may also be sufficient to potentiate RIG-I and MDA5, as LGP2 ATPase mutant mice are significantly more susceptible to viral infection even in the presence of functional RIG-I and MDA5 (238). However, this model is further complicated by certain RNA-DNA hybrids that are able to bind RIG-I and activate ATPase activity, but don't induce IFN $\beta$ expression (75). It is currently undetermined whether such hybrids can sterically inhibit RIG-I due to the presence of mostly dNTPs or whether they inhibit RIG-I in a yet undescribed way.

Recent kinetic studies of RIG-I and MDA5 activation by PAMP (dsRNA) help illustrate how ATPase activity is critical for their function and distinction between host (self) and foreign (non-self) RNA. RIG-I binding to ATP is sufficient for interaction with dsRNA (144, 176). RIG-I ATPase activity is inhibited in the absence of PAMP (dsRNA) by a helical arm that blocks the ATPase site (239). Upon interaction with PAMP (dsRNA), the helical arm shifts and the two helicase domains are brought together to form an active ATPase site (239). RIG-I then catalyzes ATP to break the 5'ppp dsRNA interactions within seconds. ATP is then rapidly hydrolyzed to facilitate translocation of RIG-I to the opposite dsRNA end, after which the RIG-I oligomers can form (144). On the other hand, ATP hydrolysis drives rapid disassociation of RIG-I from host RNA features. These features include dsRNA with a $5^{\prime}$ monophosphate group $(174,175)$ that is 
found in mRNA after decapping during the mRNA degradation process $(177)$ and 3 ' overhang RNA $(144,170)$ found in miRNA (240) as well as other RNA motifs, such as $5^{\prime} \mathrm{OH}$ RNA (144, 176) found in bacteria (241). Furthermore, an impaired ATPase functionality increases the promiscuity of RIG-I binding these host RNA motifs (144, 176, 242).

Similar ATPase functions have been found during MDA5 filamentous formation. The $\mathrm{C}$ terminus of MDA5 is critical to form organized helical filaments (138) and ATP binding drives association and hydrolysis and disassociation from foreign dsRNA [with little coordination being observed between neighboring MDA5 proteins (137)] in a manner that involves MDA5 twisting along its flexible and hydrophobic interface domains (243). Taken together, ATPase activity may be directed toward rapid disassociation from host dsRNA and degradation of RNA-DNA hybrids, but primarily act on the translocation pathway upon interaction with PAMP (dsRNA). It is also possible that host and hybrid dsRNAs could inactivate RIG-I independently of their ability to bind the C-terminus and activate ATPase activity. This has been shown, for example, for a hybrid RNA that has one strand consists mostly of DNA except at positions 2 and 5, which appears to bind RIG-I and activate its ATPase activity but doesn't activate IFN1 signaling (75). Future studies are needed in order to determine these differential interaction mechanisms.

\section{NOVEL MECHANISMS OF INHIBITION OR ACTIVATION OF RIG-I AND MDA5 BY CELLULAR RNAs}

Contrary to the traditional paradigm, there is increasing evidence to suggest that RIG-I and MDA5 interact with certain host RNA motifs, resulting in auto-activation or auto-inhibition of the IRF pathway (Figure 5). One of the most strongly supported models is activation by host and viral circular RNAs (circRNA). Originally found in a variety of pathogen genomes, circRNAs in eukaryotic cells were first thought to be byproducts of the premRNA splicing process. However, they have later been found to be produced by a non-canonical "backsplicing" process and there is increasing evidence to suggest that they play some important regulatory roles (244), suggesting that they may have specifically evolved for this purpose. RIG-I was first found to interact with circRNA produced in situ (245). Interestingly, the minimum component required for RIG-I activation is an intron of pathogenic origin to be spliced out during the circularization process. As human introns have been found to be associated with many RNA binding proteins, it is speculated that these proteins may have prevented circularization of this particular synthetic circRNA used in this study (245) and that host RNA binding proteins normally prevent endogenous circRNAs from being detected by the innate immune system. Nevertheless, some viral infections can potentially expose these endogenous circRNAs for immune detection, as has recently been found to be the case for a novel host-derived circRNA (lnc-Lsm3b) that is IFN-inducible and shows a down-regulation of its binding to host proteins during viral infection and therefore appears to compete with viral dsRNA as an inhibitor of the RIG-I signaling feedback loop (198). Similar inhibitory mechanisms have also been noted for RNA products of the exonuclease SKIV2L (246). Finally, recent studies have found that hepatitis $\mathrm{C}$ virus (HCV) infection increases the expression of certain cellular RNAs that can inhibit RIG-I function. HCV infection increased the mRNA levels of hepatic selenoprotein, which was able to bind to RIG-I through a hairpin structure and inactivated it during viral infection (247). Infection by HCV, vesicular stomatitis virus (VSV), or Sendai virus, or direct exposure of cells to type 1 and 3 interferons increases expression of the cellular long non-coding RNA (lncRNA), namely lncATV, which similarly inhibits RIG-I function by directly interacting with it in order to promote virus replication (248). In addition to the greatly increased implications of RIG-I and MDA5 modulation, these findings also have significant implications in characterizing new biomarkers of disease, as increased serum selenoprotein level has been found to significantly associate with treatment failure of anti-viral drugs in HCV patients, and can possibly explain the increased prevalence of type 2 diabetes in $\mathrm{HCV}$ patients (247).

Cellular RNA has also been found to activate RLR signaling during viral infection. Vault RNAs, which are transcribed from four genes and are normally found in large ribonucleoprotein complexes in cytoplasmic "vaults," are significantly enriched for binding to RIG-I during infection with KSHV (29). This may be due partly to viral infection-induced reduction in the level of cellular triphosphatase DUSP11, which dephosphorylates the 5'ppp group on the vault RNAs, as they could only be immunogenic (in the absence of viral infection) by the addition of the 5'ppp group. RIG-I and MDA5 have also been found to be activated by RNA microparticles produced in situ by rolling circle transcription, generating tandem repeat RNA strands (249). Retrotransposons may also be able to activate both RIG-I and MDA5, as both can be activated by LINE1 RNA independently of DNA sensing mechanisms and retrotransposition (250).

Viral infections can also induce recognition of host RNAs. Herpes Simplex Virus 1 (HSV1) infection, for example, has been shown to induce translocation of the host pseudogene RNA5SP141 ribosomal RNA into the cytosol to bind to RIGI. Knockdown of RNA5SP141 decreased cytokine signaling during infection with HSV and EBV as well as influenza A virus (IAV) (251). RIG-I has also been found to be activated by hairpin RNA structures generated by cleavage of RNA by RNase L, which has been demonstrated to occur during HCV infection (179) as well as from mitochondrial dsRNA produced in p53 deficient mice (180). The mitochondria, in particular, may be an important source of immunostimulatory host dsRNA. Viral infections are well-known to cause mitochondrial damage (252). Knockdown and hepatocyte-specific conditional $\mathrm{KO}$ of mitochondrial RNA degrading enzymes resulted in the increase of cytoplasmic mitochondrial dsRNA which was able to activate MDA5 (253). Additionally, extracellular vesicles (EV) secreted by apoptotic endothelial cells were found to contain long interspersed nuclear element (LINE) and short interspersed nuclear element (SINE) RNAs that are products 
of RNA polymerase III and were able to activate RIG-I signaling (254). Collectively, these findings demonstrate the many unique ways by which cellular RNAs can modulate RIG-I and MDA5 functions as well as the potential implications of RIGI activation by pharmaceuticals as an anti-viral or generalized immunotherapy, though much caution and studies would still be needed to determine the appropriate levels of RIG-I and MDA5 activation.

\section{VIRAL MODULATIONS OF RIG-I AND MDA5 FUNCTIONS}

Given that RIG-I and MDA5 are critical for activating expression of IFN1 during viral infection, there is much interest in studying the interactions of these cellular proteins with viral factors (RNAs or proteins), as the ability to modulate interferon expression is a major evolutionary driving force in viral evolution (255, 256). There are many mechanisms viruses have evolved to evade RIG-I and MDA5 signaling, which have been discussed at length elsewhere $(257,258)$. Such mechanisms are of particular importance to segmented RNA viruses, providing potentially more dsRNAs for RIG-I and MDA5 activation (259). IAV and the other orthomyxoviruses are unique in that they replicate in the nucleus of the cells (260), preventing the viral RNA from being detected by the PRRs. However, recent preliminary evidence seems to suggest that RIG-I may also endogenously be present in the nucleus and performs similar viral RNA binding and activation of the IFN1 pathway (261), yet this finding has yet to be replicated by other laboratories.

There is also increasing evidence to suggest that RNA processing is another mechanism of immune modulation. Certain bunyaviruses can cleave the $5^{\prime}$ tri-phosphate group from their genomic RNA (262) in order to avoid immune detection. RIG-I has also been found to be subjected to negative modulation by RNAi during IAV infection (263). On the contrary, nucleoproteins from the Sendai virus (264) regulate the number of DI particles being produced, and IAV nucleoproteins also regulate the production of abortive replication RNA (208), mini viral RNAs (265) and DVG RNA (208), all of which are immunostimulatory. The Semliki Forest virus (SFV) polymerase has even been found to convert host RNA into $5^{\prime}$-ppp dsRNA to induce IFN1 expression (266). This raises an intriguing possibility that induction of IFN1 may actually benefit some viruses under certain circumstances despite IFN1 signaling negatively regulating viral replication.

The viral RNA levels and localization throughout the viral life cycle might also play an important role in immune evasion (267). Control of viral RNA levels by viral exoribonucleases in particular illustrates the complicated balance between viral production and immune evasion for optimal viral propagation, as has found to be the case for arenaviral nucleoproteins (NPs) $(268,269)$ and nonstructural proteins found in coronaviruses $(270,271)$. Finally, viral infection has the capability to disrupt processes of the cell's basic functions, such as transcription and translation, thereby affecting viral replication and immune signaling in complicated ways (258).
One of the most significant ways viruses modulate RIGI and MDA5 signaling is through their viral proteins (272) (Figure 6). The respiratory syncytial virus (RSV) non-structural protein (NS2) protein and the Z matrix proteins of pathogenic arenaviruses interact with the RIG-I CARD domains to block its interaction with MAVS $(273,274)$. The HSV1 deamidase UL37 specifically targets RIG-I through its helicase domain, abrogating its ability to bind to RNA (275). The IAV polymerase components also interact directly with RIG-I (276), though their biological significance has yet to be determined as they don't significantly affect IFN1 production. On the other hand, RNA binding appears to be an important bridge between the interaction of RIG-I with other viral proteins, as the nucleoproteins (NPs) of IAV (276) and arenaviruses $(277,278)$ both interact with RIG-I through viral RNA. The NS1 protein of rotaviruses targets RIG-I for degradation that is independent of proteasomes (279). The V protein of paramyxoviruses inhibits MDA5 (40) by targeting a unique feature of the ATP binding pocket in MDA5 (280) and by inhibiting MDA5 CARD dephosphorylation (93), but can also inhibit RIG-I by interacting with the CARD domain to prevent its ubiquitination by TRIM25 (281). Finally, the US11 protein of HSV1 (282) and the arenaviral Z matrix proteins (274) directly interact with and inhibit RIG-I and MDA5 in a similar fashion. There are also many other viral proteins that can regulate proteins in the RIG-I and MDA5 pathways, which have been discussed in detail elsewhere $(44,53,59,96,257,283)$.

\section{MODULATIONS OF RIG-I AND MDA5 FUNCTIONS BY THEIR POST-TRANSLATIONAL MODIFICATIONS AND/OR BY OTHER VIRAL OR CELLULAR PROTEINS}

It is important to consider the different regulatory mechanisms of RIG-I and MDA5 when considering their different functionalities (Figures 4, 6). One of the key differences between these proteins is in their post-translation modifications (96). Ubiquitination of RIG-I is necessary for its activation (118) and is a point of negative regulation by host proteins $(117,284,285)$, viral proteins $(281,286,287)$ and ubiquitin mimics (288) as well as positively regulated by influenza B NS1 protein (289) and another ubiquitin mimic (290). On the contrary, MDA5 is more well-known to be negatively regulated by ubiquitination (291), with positive regulation by K63 ubiquitination being more controversial. While the deubiquitinase USP3 inhibits MDA5 as well as RIG-I, it is thought that this may be due to USP3 directly binding the MDA5 CARD domain to prevent RNA filamentation (284). This raises the question of how RIG-I can maintain its stability outside of the proteasome, as ubiquitination at other lysine residues in RIG-I besides K172 induces proteasomal degradation (291-293). This proteasomal degradation may be mediated by a p62 autophagic complex that associates with LRRC25/ISG15 (294) and SQSTM1 (295) and also mediates mitophagy and downregulation of MAVS signaling during measles virus infection (296). 


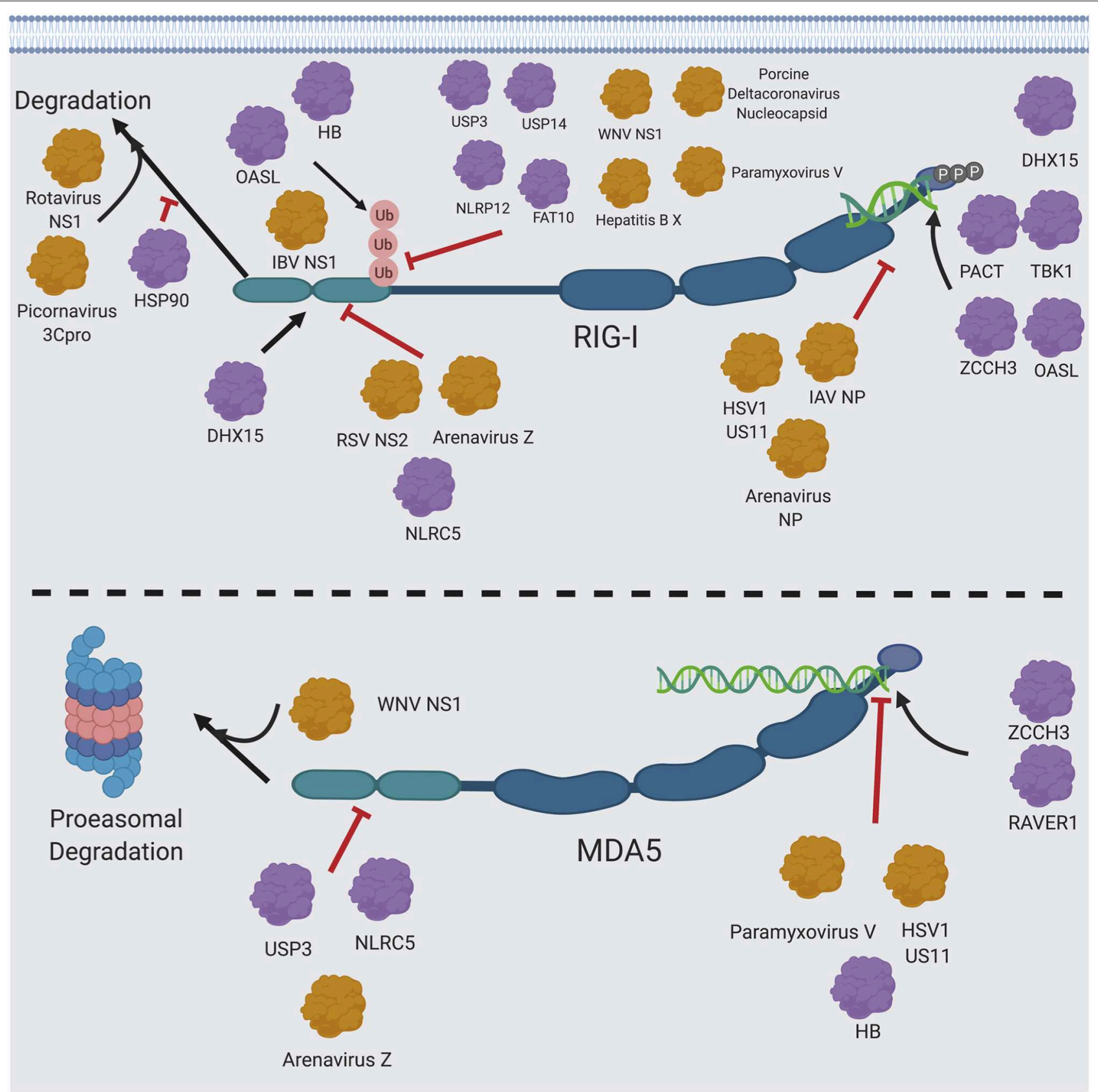

FIGURE 6 | RIG-I/MDA5 interactions with host and cellular proteins. Host proteins (shown in purple) and viral proteins (shown in orange) that modulate RIG-I and MDA5 signaling are shown. Figure created using BioRender software.

One key observation is that, while both RIG-I and MDA5 are cleaved during picornavirus infection, this cleavage is mediated by the viral proteinase $3 C^{\text {pro }}(297)$ and is independent of the proteasome (298) for RIG-I, whereas it is mediated by cellular caspases and the proteasome for MDA5 (299). MDA5 is also cleaved by caspases during apoptosis (4), though it hasn't been shown whether this is mediated by MDA5's ubiquitination sites. The ubiquitin linkage site may be a determinate of function, as the ubiquitin ligases RNF122 (300) and STUB1 $(293,301)$ have been shown to negatively regulate RIG-I catalyzed K48linked ubiquitination as opposed to the known K63-linked ubiquitination at the K172, K849 and K851 activating sites, and RNF125 has also been proposed to K48 ubiquitinate RIG-I (291) (though it hasn't been shown directly) (59). TRIM40 has also been shown to negatively regulate RIG-I and MDA5 by K27 and K48 ubiquitination (123).

Substantiating the possibility that K63 ubiquitination on RIGI may be functionally distinct from its other ubiquitination 
sites by protecting it from degradation is the finding that the NS1 protein of West Nile virus (WNV) targets both RIG-I and MDA5 for degradation by proteasomes. Additionally, NS1 inhibited K63 ubiquitination of RIG-I, but MDA5 was not found to be K63 ubiquitinated (126). Heat shock protein 90-alpha (HSP90) has been found to protect RIG-I from proteasomal degradation, but it is unknown which type of ubiquitination that is inhibited by HSP90 (302). Taken together, the experimental evidence suggests that RIG-I may be protected from proteasome degradation despite its activating ubiquitin moieties (52). This warrants further studies for mechanistic elucidation.

RIG-I and MDA5 additionally interact with different cellular co-factors, contributing to their differential regulations of function. RIG-I is well-known for being potentiated by proteins that also bind dsRNA, such as (PACT) $(303,304)$, which was first discovered as a protein activator of PKR, the serine/threonineprotein kinase 1 (TBK1) (305-309) and the oligoadenylate synthetase L (OASL) (310). PACT in particular has some functional similarities to RIG-I, as they each contain three distinct RNA binding domains (311) and interact with many of the same cellular co-factors, such as PKR (312) and Dicer (312, 313). Because of the important role of PACT in augmenting RIGI function, it is a prime target for inhibition of RIG-I signaling by several viral proteins from diverse families of viruses (314-316), the molecular mechanisms of PACT inhibition by these viral proteins can vary and still need to be characterized in detail in future studies. Similarly, the host ribonucleoprotein RAVER1 can increase affinity of MDA5 for dsRNA (317), and the zinc-finger protein ZCCHC3 has recently been found do so for both RIGI and MDA5 (125) in similar mechanisms to the other known RNA-binding proteins. On the contrary, the human hemoglobin subunit beta $(\mathrm{HB})$ has recently been suggested to decrease MDA5 signaling by competing for long dsRNA, while HB can enhance RIG-I signaling by increasing K63 ubiquitination on RIG-I (318).

Several host factors interacting with RIG-I and MDA5 do so by yet undescribed mechanisms. PKR [which is also activated by PACT $(319,320)$ and is sequestered by the cellular helicase DHX36 protein to form stress granules $(321,322)$ along with RIG-I $(323,324)$ and TRIM25 (324)] appears to have a novel and yet uncharacterized function in enhancing MDA5-dependent MAVS signaling that is dependent on the kinase activity of PKR (325). Additionally, the porcine Interferon-Inducible Oligoadenylate Synthetase-like protein (pOASL) has also been found to interact with and inhibit MDA5 by an unknown mechanism (326).

The RIG-I CARD domain interacts with MAVS to induce interferon signaling, so proteins that disrupt this interaction [as it has been proposed for the Atg5 and Atg12 autophagy proteins (59)] can specifically inhibit RIG-I signaling. However, other cellular proteins, such as the complement protein $\mathrm{gClqR}$ (327) and TARBP2 (328) that interact directly with MAVS, inhibit both RIG-I and MDA5. Lactate and hexokinase have also recently been found to inhibit RIG-I and MDA5 by interacting with MAVS, which may be significant in explaining the interplay between metabolism and immune signaling as glycolysis was found to be greatly decreased upon RLR signaling (329). Likewise, cellular proteins, such as NLRC5 (330) that interacts with the RIG-I and MDA5 CARD domains have been shown to block interaction of both RIG-I and MDA5 with MAVS. Contrarily, DHX15 has been identified as a RIG-I cofactor that interacts with the RIG-I CARD domains and with PAMP (dsRNA), thereby increasing RIG-I ATPase activity (331). Additionally, ADP-ribosylation factor proteins can block RIG-I and MDA5 from interacting with PAMPs and thereby inhibit their activation (332, 333). Lastly, the green tea molecule EGCG has also been shown to inhibit the ATPase function of RIG-I (334). The similarities and differences between RIG-I and MDA5 modulations and signaling are complex and will need to be elucidated further in future studies.

\section{EVOLUTION AND SPECIATION OF RIG-I/MDA5 AND RIG-I/MDA5-LIKE PROTEINS}

Despite their structural and mechanistic differences, it is important to emphasize that existing phylogenetic analysis indicates that RIG-I and MDA5 come from a common origin that is also shared among several other protein families (Figure 7). The linkage of the helicase and $\mathrm{DExD} / \mathrm{H}$ box protein appear to be ancient, as orthologs of these proteins are found in the Archaea kingdom $(335,336)$. MDA5 orthologs are found in most vertebrates (184), while RIG-I orthologs are only found in mammals, ducks, geese and some selected fish and reptiles (184, 337-343) (Figures 2, 7).

It is therefore likely that MDA5 evolved first, perhaps from a common ancestor with the closely related LGP2 helicase family (184), which is structural similar to RIG-I and MDA5 but lacks the CARD domains at its $\mathrm{N}$ terminus (185). LGP2 orthologs are also only found in vertebrates while the next closest related family of proteins (Dicer) are more ancient proteins. It has therefore been proposed that the RIG-I helicase- $\mathrm{DExD} / \mathrm{H}$ complex may have been duplicated from MDA5 in the common ancestor of vertebrates (184). The association of the two CARD domains appears to have followed, as individual CARD domains are found in a variety of vertebrates that also encode caspases $(344,345)$, but only RIG-I, MDA5, and certain members of the Nacht family of NTPases (346) have two CARD domains. Phylogenetic analysis has shown that the helicase-DExD/H and CARD2 have strong co-evolution history $(347,348)$, while CARD1 has evolved more independently (184). CARD2 appears to have been grafted onto the RIG-I helicase-DExD/H complex first, with the CARD2MDA5 being duplicated from this event. Finally, CARD1 was grafted onto the CARD2-helicase-DExD/H complex in separate events for RIG-I and MDA5 (184). In mammals, positive selection can be seen in the flexible hinge region connecting the CARD domains to the helicase in RIG-I and MDA5. RIGI contains an additional site of positive selection within the Hel1 structural motif (N421), while most of the unique positive selection sites for MDA5 are in regions specific to it, including a 29 amino acid insertion in Hel2 (349).

While RIG-I and MDA5 may both originate from common ancestors of vertebrates, there is increasing evidence to suggest 


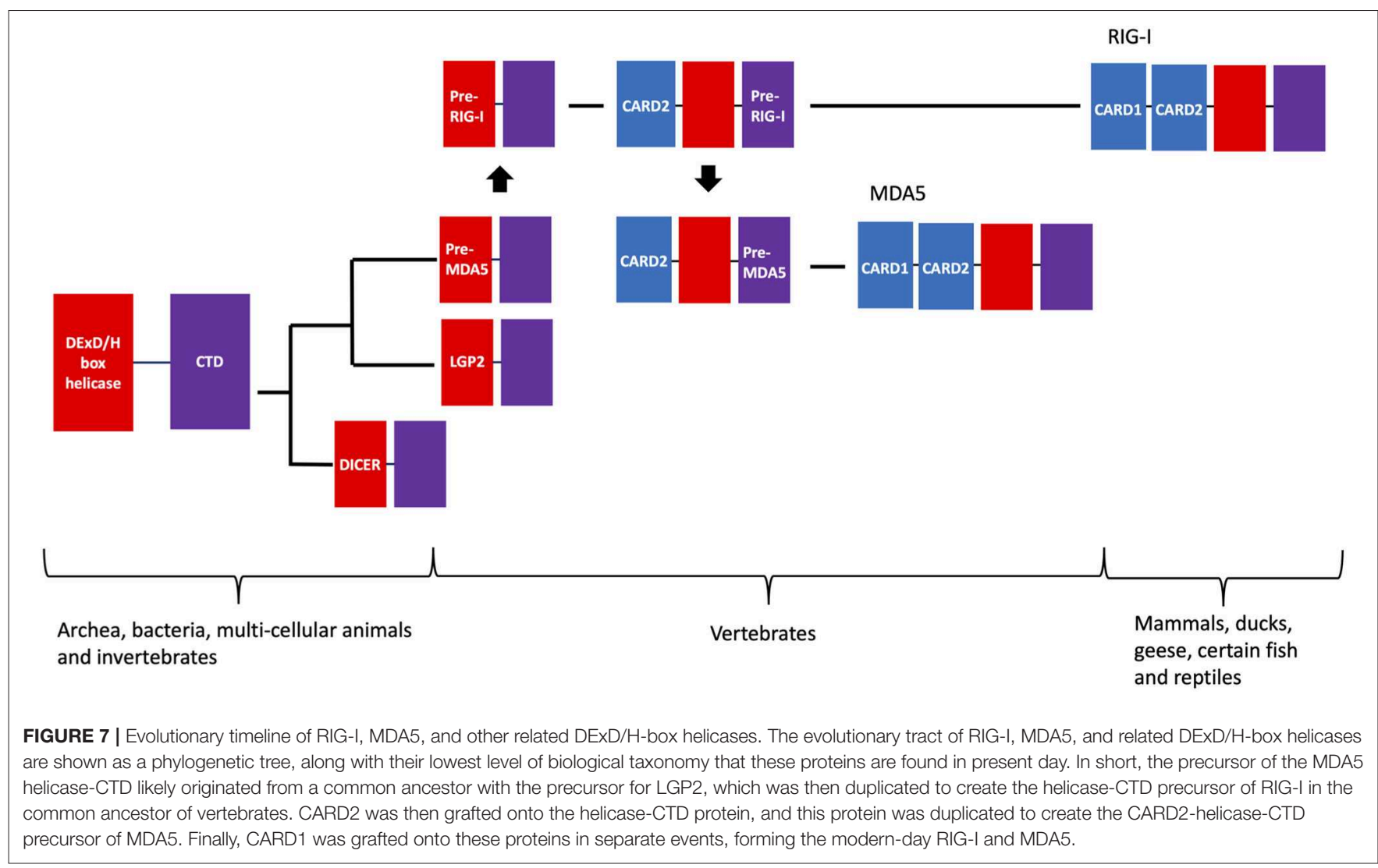

that proteins with similar functions may have evolved separately in other species from ancient helicase- $\mathrm{DExD} / \mathrm{H}$ proteins, implicating RNA-mediated defense responses as a potentially universal biological function. A RIG-I homolog has recently been found in a planarian that is able to activate downstream inflammatory genes in the absence of the traditional CARD domains (350), and a similar homolog in Caenorhabditis elegans has been proposed to mediate anti-viral RNAi by complexing with Dicer and catalyzing their translocation on the viral genome (351). Additionally, insects have been found to primarily respond to RNA viruses by RNAi mediated by Dicer proteins (352). Dicer may potentially mediate dsRNA-activated anti-viral signaling pathways that is independent of RNAi pathways, as has been found to be the case for the expanded CAG-repeat dsRNA (353). Pattern recognition receptors (PRRs) that respond to viral RNA have not yet been found outside of the animal kingdom, as RLRlike proteins in prokaryotes do not have CARD domains and the PRRs in plants found so far are surface-receptor kinases that respond to external molecular elements of bacteria (354) [similar to the mammalian toll-like receptors (TLRs)]. However, RNA silencing has been demonstrated to be an important anti-viral strategy in plants $(354,355)$ and certain Arabidopsis mutants appear to be more susceptible to infection by RNA viruses (356).

RIG-I (357) and MDA5 $(357,358)$ are known to influence antiviral signaling in zebrafish (Danio rerio) and other fish species $(357,359-361)$ through the canonical MAVS signaling pathway. Fish RIG-I like receptors (RLRs) have been shown to be regulated by the expression of alternate splicing isoforms $(358,362)$, which have also been found to occur with a dominant-negative splice variant of the human RIG-I (363). RIGI and MDA5 have also been found to participate in anti-viral signaling in ducks (364-367) and geese $(340,368,369)$, and MDA5 alone in chickens (370-372) and other birds (373). The observation across species of RLR's performing compensatory mechanisms when a function or a pathway protein is absent is reiterated in birds, as MDA5 has been found to sense short and long dsRNA in chickens (372) and in the Chinese shrew (374), both of which lack RIG-I. Additionally, TRIM25 activates RIG-I in ducks (364) and in the Chinese goose (375) in the absence of the K172 activating ubiquitin binding site that is conserved in primates and some rodents (364). Finally, the rainbow trout (Oncorhynchus mykiss) has been found to express a LGP2 variant in addition to the canonical LGP2 that contains an incomplete C-terminal domain of RIG-I (376). The differential presence of PRRs may also influence viral evolution. A mutation in the IAV polymerase subunit PB2 found in avian-adapted H1N1 strains decreases the inhibition of human RIG-I function by IAV nucleoproteins, which may indicate a differential selective pressure for viruses that propagate in species that don't contain RIG-I (377). The evolutionary pattern and compensatory mechanisms of RLRs across species implicate them as critical for anti-viral function, and that evolutionary forces drive the available pathway proteins to meet these functional needs. Future studies need to be done to further 
differentiate RLR function among the different species, as this will provide critical information concerning the various methods of disease control by targeting the pathogen by these important host proteins.

There is also increasing evidence for other RNA-sensing $\mathrm{DExD} / \mathrm{H}$ helicases serving important roles in anti-pathogen immune sensing, which have recently been reviewed elsewhere (187). Some RNA helicase (DDX) proteins appear to serve as complex proteins upon interacting with viral RNA. DDX3 is a well-known example, being suspected of being a transcription factor for IFN- $\beta$ (378), associating with spliceosomes and the stress-induced p-bodies to influence mRNA splicing and decay, respectively $(322,378)$, and interacting with the MAVS complex during viral infection conditions $(378,379)$. In particular, DDX3 associating with MAVS has been found to be important for anti-viral control against several viruses (378380), and since the two DDX3 homologs are found on the $\mathrm{X}$ and $\mathrm{Y}$ chromosomes, they may contribute to immunological differences between genders (381). This is a repeated theme, as DHX9 (382), DHX15 (383), and a complex consisting of DDX1/DDX21/DHX36 (384) have also been found to associate with the MAVS complex to enhance IFN1 signaling, while DHX33 interacts with MAVS independently of viral infection (385). DDX proteins can also activate other proteins in the IRF pathway. Multiple DDX proteins can interact with IKKE, with DDX3 being phosphorylated by IKK $\varepsilon$ to induce IRF3 interaction with the TBK1-IKKE complex (378), and DDX19 blocking this interaction to inhibit IFN1 signaling (386). Similar control mechanisms have been demonstrated for DDX3 interacting with viral proteins. For example, DDX3 has recently been found to associate with arenaviral NPs to increase viral RNA synthesis and IFN1 expression (387). Additionally, the NP of the 1918 H1N1 IAV pandemic strain has been shown to target DDX3 for degradation as a potential mechanism of virulence (388). DHX15 (389) and DHX33 have also been found to activate NFאB and

\section{REFERENCES}

1. Sun YW. RIG-I, a human homolog gene of RNA helicase, is induced by retinoic acid during the differentiation of acute promyelocytic leukemia cell. Biochem Biophys Res Commun. (1997) 292:274-9.

2. Imaizumi T, Aratani S, Nakajima T, Carlson M, Matsumiya T, Tanji K, et al. Retinoic acid-inducible gene-I is induced in endothelial cells by LPS and regulates expression of COX-2. Biochem Biophys Res Commun. (2002) 292:274-9. doi: 10.1006/BBRC.2002.6650

3. Kang D, Gopalkrishnan RV, Wu Q, Jankowsky E, Pyle AM, Fisher PB. mda-5: an interferon-inducible putative RNA helicase with double-stranded RNAdependent ATPase activity and melanoma growth-suppressive properties. Proc Natl Acad Sci USA. (2002) 99:637-42. doi: 10.1073/PNAS.022637199

4. Kovacsovics M, Martinon F, Micheau O, Bodmer J-L, Hofmann K, Tschopp J. Overexpression of helicard, a CARD-containing helicase cleaved during apoptosis, accelerates DNA degradation. Curr Biol. (2002) 12:83843. doi: 10.1016/S0960-9822(02)00842-4

5. Randall RE, Goodbourn S. Interferons and viruses: an interplay between induction, signalling, antiviral responses and virus countermeasures. J Gen Virol. (2008) 89:1-47. doi: 10.1099/vir.0.83391-0

6. Jacobs JL, Coyne CB. Mechanisms of MAVS regulation at the mitochondrial membrane. J Mol Biol. (2013) 425:5009-19. doi: 10.1016/j.jmb.2013.10.007
MAPK signaling pathways. Finally, DDX60 has been shown to act as a cofactor for RIG-I $(390,391)$ and DHX29 for MDA5 (392). Taken altogether, these cellular proteins have likely evolved to regulate RIG-I and MDA5 signaling from their common $\mathrm{DExD} / \mathrm{H}$ helicase predecessors.

\section{SUMMARY AND FUTURE OUTLOOKS}

As our capacity to study the molecular mechanisms and to purposefully modulate immune responses increases in specificity, so will our needs to characterize the differences between related immune signaling proteins. The concept of personalized medicine derives from the idea that we can therapeutically intervene in a situation that is designed around the individual's unique characteristics. While this is an achievable realm of medicine in the future, an immediate step is to determine the functions of some critical proteins, such as the RIG-I and MDA5 of the innate immune arm. Examining their structural and functional similarities and differences at multiple levels will allow for a deeper level of appreciation of these proteins, which may be exploited therapeutically to differentially modulate RIG-I and MDA5 signalings by different RNA ligands (43, 191, 393, 394) or other pharmaceutical compounds (395) toward the goal of achieving personalized medicine.

\section{AUTHOR CONTRIBUTIONS}

$\mathrm{MB}$ and HL contributed to the literature review and writing of the manuscript. MB prepared all figures with inputs from HL.

\section{FUNDING}

This work was supported in part by NIH NIAID grant R01 AI131586 to HL and by a pre-doctoral NIH fellowship T32 DA007097 to MB.

7. Vazquez C, Horner SM. MAVS coordination of antiviral innate immunity. $J$ Virol. (2015) 89:6974-7. doi: 10.1128/JVI.01918-14

8. Tan P, He L, Cui J, Qian C, Cao X, Lin M, et al. Assembly of the WHIP-TRIM14-PPP6C mitochondrial complex promotes RIG-I-mediated antiviral signaling. Mol Cell. (2017) 68:293307.e5. doi: 10.1016/J.MOLCEL.2017.09.035

9. Kouwaki T, Okamoto M, Tsukamoto H, Fukushima Y, Matsumoto M, Seya T, et al. Zyxin stabilizes RIG-I and MAVS interactions and promotes type I interferon response. Sci Rep. (2017) 7:11905. doi: 10.1038/s41598-017-12224-7

10. Fitzgerald KA, McWhirter SM, Faia KL, Rowe DC, Latz E, Golenbock DT, et al. IKKE and TBK1 are essential components of the IRF3 signaling pathway. Nat Immunol. (2003) 4:491-6. doi: 10.1038/ ni921

11. Sharma S, TenOever BR, Grandvaux N, Zhou G-P, Lin R, Hiscott J. Triggering the interferon antiviral response through an IKKrelated pathway. Science. (2003) 300:1148-51. doi: 10.1126/science.10 81315

12. tenOever BR, Ng S-L, Chua MA, McWhirter SM, Garcia-Sastre A, Maniatis T. Multiple functions of the IKK-related kinase IKKe in interferon-mediated antiviral immunity. Science. (2007) 315:1274-8. doi: 10.1126/science.1138527 
13. Paz S, Sun Q, Nakhaei P, Romieu-Mourez R, Goubau D, Julkunen I, et al. Induction of IRF-3 and IRF-7 phosphorylation following activation of the RIG-I pathway. Cell Mol Biol. (2006) 52:17-28.

14. Ning S, Pagano JS, Barber GN. IRF7: activation, regulation, modification and function. Genes Immun. (2011) 12:399-414. doi: 10.1038/gene.2011.21

15. Mingzhu Zhu G, Fang T, Li S, Meng K. Activity of IFN regulatory factor 3 controls nuclear import and DNA-binding bipartite nuclear localization signal. J Immunol. (2015) 195:289-97. doi: 10.4049/jimmunol.1500232

16. Newton K, Dixit VM. Signaling in innate immunity and inflammation. Cold Spring Harb Perspect Biol. (2012) 4:a006049. doi: 10.1101/cshperspect.a006049

17. Kell AM, Gale M Jr. RIG-I in RNA virus recognition. Virology. (2015) 479-80:110-21. doi: 10.1016/j.virol.2015.02.017

18. Kato H, Takeuchi O, Sato S, Yoneyama M, Yamamoto M, Matsui $\mathrm{K}$, et al. Differential roles of MDA5 and RIG-I helicases in the recognition of RNA viruses. Nature. (2006) 441:101-5. doi: 10.1038/nature 04734

19. Weber-Gerlach M, Weber F. Standing on three legs: antiviral activities of RIG-I against influenza viruses. Curr Opin Immunol. (2016) 42:715. doi: 10.1016/J.COI.2016.05.016

20. Spengler JR, Patel JR, Chakrabarti AK, Zivcec M, García-Sastre A, Spiropoulou CF, et al. RIG-I mediates an antiviral response to crimean-congo hemorrhagic fever virus. J Virol. (2015) 89:10219-29. doi: 10.1128/JVI.01643-15

21. Yamada S, Shimojima M, Narita R, Tsukamoto Y, Kato H, Saijo M, et al. RIG-I-like receptor and toll-like receptor signaling pathways cause aberrant production of inflammatory cytokines/chemokines in a severe fever with thrombocytopenia syndrome virus infection mouse model. J Virol. (2018) 92:e02246-17. doi: 10.1128/JVI.02246-17

22. Spiropoulou CF, Ranjan P, Pearce MB, Sealy TK, Albariño CG, Gangappa S, et al. RIG-I activation inhibits ebolavirus replication. Virology. (2009) 392:11-5. doi: 10.1016/J.VIROL.2009.06.032

23. Furr SR, Moerdyk-Schauwecker M, Grdzelishvili VZ, Marriott I. RIG-I mediates nonsegmented negative-sense RNA virus-induced inflammatory immune responses of primary human astrocytes. Glia. (2010) 58:16209. doi: 10.1002/glia.21034

24. Loo Y-M, Fornek J, Crochet N, Bajwa G, Perwitasari O, Martinez-Sobrido $\mathrm{L}$, et al. Distinct RIG-I and MDA5 signaling by RNA viruses in innate immunity. J Virol. (2008) 82:335-45. doi: 10.1128/JVI.01080-07

25. Deddouche S, Goubau D, Rehwinkel J, Chakravarty P, Begum S, Maillard PV, et al. Identification of an LGP2-associated MDA5 agonist in picornavirusinfected cells. Elife. (2014) 3:e1535. doi: 10.7554/eLife.01535

26. Luo R, Xiao S, Jiang Y, Jin H, Wang D, Liu M, et al. Porcine reproductive and respiratory syndrome virus (PRRSV) suppresses interferon- $\beta$ production by interfering with the RIG-I signaling pathway. Mol Immunol. (2008) 45:2839-46. doi: 10.1016/J.MOLIMM.2008.01.028

27. van Kasteren PB, Beugeling C, Ninaber DK, Frias-Staheli N, van Boheemen S, Garcia-Sastre A, et al. Arterivirus and nairovirus ovarian tumor domaincontaining deubiquitinases target activated RIG-I to control innate immune signaling. J Virol. (2012) 86:773-85. doi: 10.1128/JVI.06277-11

28. Zhang Z, Filzmayer C, Ni Y, Sültmann H, Mutz P, Hiet M-S, et al. Hepatitis $\mathrm{D}$ virus replication is sensed by MDA 5 and induces IFN- $\beta / \lambda$ responses in hepatocytes. J Hepatol. (2018) 69:25-35. doi: 10.1016/j.jhep.2018.02.021

29. Zhao Y, Ye X, Dunker W, Song Y, Karijolich J. RIG-I like receptor sensing of host RNAs facilitates the cell-intrinsic immune response to KSHV infection. Nat Commun. (2018) 9:4841. doi: 10.1038/s41467-018-07314-7

30. Ye W, Chew M, Hou J, Lai F, Leopold SJ, Loo HL, et al. Microvesicles from malaria-infected red blood cells activate natural killer cells via MDA5 pathway. PLoS Pathog. (2018) 14:e1007298. doi: 10.1371/journal.ppat.1007298

31. Qin C-F, Zhao H, Liu Z-Y, Jiang T, Deng Y-Q, Yu X-D, et al. Retinoic acid inducible gene-I and melanoma differentiation-associated gene 5 are induced but not essential for dengue virus induced type I interferon response. Mol Biol Rep. (2011) 38:3867-73. doi: 10.1007/s11033-010-0502-7

32. Nasirudeen AMA, Wong $\mathrm{HH}$, Thien $\mathrm{P}, \mathrm{Xu} \mathrm{S}$, Lam K-P, Liu DX. RIG-I, MDA5 and TLR3 synergistically play an important role in restriction of dengue virus infection. PLoS Negl Trop Dis. (2011) 5:e926. doi: 10.1371/journal.pntd.0000926
33. Fredericksen BL, Keller BC, Fornek J, Katze MG, Gale M. Establishment and maintenance of the innate antiviral response to West Nile virus involves both RIG-I and MDA5 signaling through IPS-1 ${ }^{\dagger}$. J Virol. (2008) 82:60916. doi: 10.1128/JVI.01305-07

34. Errett JS, Suthar MS, McMillan A, Diamond MS, Gale M. The essential, nonredundant roles of RIG-I and MDA5 in detecting and controlling West Nile virus infection. J Virol. (2013) 87:11416-25. doi: 10.1128/JVI.01488-13

35. Sanchez David RY, Combredet C, Sismeiro O, Dillies M-A, Jagla B, Coppée J$\mathrm{Y}$, et al. Comparative analysis of viral RNA signatures on different RIG-I-like receptors. Elife. (2016) 5:e11275. doi: 10.7554/eLife.11275

36. Gitlin L, Benoit L, Song C, Cella M, Gilfillan S, Holtzman MJ, et al. Melanoma Differentiation-Associated Gene 5 (MDA5) is involved in the innate immune response to paramyxoviridae infection in vivo. PLoS Pathog. (2010) 6:e1000734. doi: 10.1371/journal.ppat.1000734

37. Grandvaux N, Guan X, Yoboua F, Zucchini N, Fink K, Doyon P, et al. Sustained activation of interferon regulatory factor 3 during infection by paramyxoviruses requires MDA5. J Innate Immun. (2014) 6:65062. doi: $10.1159 / 000360764$

38. Kim W-K, Jain D, Sánchez MD, Koziol-White CJ, Matthews K, Ge MQ, et al. Deficiency of melanoma differentiation-associated protein 5 results in exacerbated chronic postviral lung inflammation. Am J Respir Crit Care Med. (2014) 189:437-48. doi: 10.1164/rccm.201307-1338OC

39. Broquet AH, Hirata Y, McAllister CS, Kagnoff MF. RIGI/MDA5/MAVS are required to signal a protective IFN response in rotavirus-infected intestinal epithelium. J Immunol. (2011) 186:1618-26. doi: 10.4049/JIMMUNOL.1002862

40. Yoneyama M, Kikuchi M, Matsumoto K, Imaizumi T, Miyagishi M, Taira $\mathrm{K}$, et al. Shared and unique functions of the DExD/H-box helicases RIG-I, MDA5, and LGP2 in antiviral innate immunity. J Immunol. (2005) 175:28518. doi: 10.4049/JIMMUNOL.175.5.2851

41. Kato H, Sato S, Yoneyama M, Yamamoto M, Uematsu S, Matsui K, et al. Cell type-specific involvement of RIG-I in antiviral response. Immunity. (2005) 23:19-28. doi: 10.1016/J.IMMUNI.2005.04.010

42. Wang Y, Zhang H-X, Sun Y-P, Liu Z-X, Liu X-S, Wang L, et al. Rig-I -/mice develop colitis associated with downregulation of Gai2. Cell Res. (2007) 17:858-68. doi: 10.1038/cr.2007.81

43. Kasumba DM, Grandvaux N. Therapeutic targeting of RIG-I and MDA5 might not lead to the same Rome. Trends Pharmacol Sci. (2018) 40:11627. doi: 10.1016/j.tips.2018.12.003

44. Ng CS, Kato H, Fujita T. Fueling type I interferonopathies: regulation and function of type I interferon antiviral responses. J Interf Cytokine Res. (2019). doi: 10.1089/jir.2019.0037. [Epub ahead of print].

45. Peckham D, Scambler T, Savic S, McDermott MF. The burgeoning field of innate immune-mediated disease and autoinflammation. J Pathol. (2017) 241:123-39. doi: 10.1002/path.4812

46. Czerkies M, Korwek Z, Prus W, Kochanczyk M, Jaruszewicz-Błonska J, Tudelska $\mathrm{K}$, et al. Cell fate in antiviral response arises in the crosstalk of IRF, NF-кB and JAK/STAT pathways. Nat Commun. (2018) 9:493. doi: 10.1038/s41467-017-02640-8

47. Yoboua F, Martel A, Duval A, Mukawera E, Grandvaux N. Respiratory syncytial virus-mediated NF-kappa B p65 phosphorylation at serine 536 is dependent on RIG-I, TRAF6, and IKK beta. J Virol. (2010) 84:726777. doi: 10.1128/JVI.00142-10

48. Rückle A, Haasbach E, Julkunen I, Planz O, Ehrhardt C, Ludwig S. The NS1 protein of influenza A virus blocks RIG-I-mediated activation of the noncanonical NF- $\kappa$ B pathway and p52/RelB-dependent gene expression in lung epithelial cells. J Virol. (2012) 86:10211-7. doi: 10.1128/JVI.00323-12

49. Bertin J, Guo Y, Wang L, Srinivasula SM, Jacobson MD, Poyet JL, et al. CARD9 is a novel caspase recruitment domain-containing protein that interacts with BCL10/CLAP and activates NF-kappa B. J Biol Chem. (2000) 275:41082-6. doi: 10.1074/jbc.C000726200

50. Poeck H, Bscheider M, Gross O, Finger K, Roth S, Rebsamen M, et al. Recognition of RNA virus by RIG-I results in activation of CARD9 and inflammasome signaling for interleukin $1 \beta$ production. Nat Immunol. (2010) 11:63-9. doi: 10.1038/ni.1824

51. Lee N-R, Kim H-I, Choi M-S, Yi C-M, Inn K-S. Regulation of MDA5MAVS antiviral signaling axis by TRIM25 through TRAF6-mediated NF- $\mathrm{B}$ activation. Mol Cells. (2015) 38:759-64. doi: 10.14348/molcells.2015.0047 
52. Martín-Vicente M, Medrano LM, Resino S, García-Sastre A, Martínez I. TRIM25 in the regulation of the antiviral innate immunity. Front Immunol. (2017) 8:1187. doi: 10.3389/fimmu.2017.01187

53. Loo Y-M, Gale M Jr. Immune signaling by RIG-I-like receptors. Immunity. (2011) 34:680-92. doi: 10.1016/j.immuni.2011.05.003

54. Song M-S, Rossi JJ. Molecular mechanisms of Dicer: endonuclease and enzymatic activity. Biochem J. (2017) 474:160318. doi: 10.1042/BCJ20160759

55. van der Veen AG, Maillard PV, Schmidt JM, Lee SA, Deddouche-Grass $\mathrm{S}$, Borg A, et al. The RIG-I-like receptor LGP2 inhibits Dicer-dependent processing of long double-stranded RNA and blocks RNA interference in mammalian cells. EMBO J. (2018) 37:e97479. doi: 10.15252/embj.201797479

56. Takahashi T, Nakano Y, Onomoto K, Yoneyama M, Ui-Tei K. Virus sensor RIG-I represses RNA interference by interacting with TRBP through LGP2 in mammalian cells. Genes. (2018) 9:E511. doi: 10.3390/genes9100511

57. Moresco EMY, Beutler B. LGP2: positive about viral sensing. Proc Natl Acad Sci USA. (2010) 107:1261-2. doi: 10.1073/pnas.0914011107

58. Rodriguez KR, Bruns AM, Horvath CM. MDA5 and LGP2: accomplices and antagonists of antiviral signal transduction. J Virol. (2014) 88:8194200. doi: 10.1128/JVI.00640-14

59. Quicke KM, Diamond MS, Suthar MS. Negative regulators of the RIG-I-like receptor signaling pathway. Eur J Immunol. (2017) 47:61528. doi: 10.1002/eji.201646484

60. Uhlen M, Fagerberg L, Hallstrom BM, Lindskog C, Oksvold P, Mardinoglu A, et al. Tissue-based map of the human proteome. Science. (2015) 347:1260419. doi: 10.1126/science.1260419

61. Devarkar SC, Wang C, Miller MT, Ramanathan A, Jiang F, Khan AG, et al. Structural basis for $\mathrm{m} 7 \mathrm{G}$ recognition and 2'-O-methyl discrimination in capped RNAs by the innate immune receptor RIG-I. Proc Natl Acad Sci USA. (2016) 113:596-601. doi: 10.1073/pnas.1515152113

62. Wu B, Peisley A, Richards C, Yao H, Zeng X, Lin C, et al. Structural basis for dsRNA recognition, filament formation, and antiviral signal activation by MDA5. Cell. (2013) 152:276-89. doi: 10.1016/j.cell.2012.11.048

63. Wu B, Peisley A, Tetrault D, Li Z, Egelman EHH, Magor KEE, et al. Molecular imprinting as a signal-activation mechanism of the viral RNA sensor RIG-I. Mol Cell. (2014) 55:511-23. doi: 10.1016/j.molcel.2014.06.010

64. Rawling DC, Pyle AM. Parts, assembly and operation of the RIG-I family of motors. Curr Opin Struct Biol. (2014) 25:25-33. doi: 10.1016/J.SBI.2013.11.011

65. Yoneyama M, Kikuchi M, Natsukawa T, Shinobu N, Imaizumi T, Miyagishi $\mathrm{M}$, et al. The RNA helicase RIG-I has an essential function in doublestranded RNA-induced innate antiviral responses. Nat Immunol. (2004) 5:730-7. doi: 10.1038/ni1087

66. Cui S, Eisenächer K, Kirchhofer A, Brzózka K, Lammens A, Lammens K, et al. The C-terminal regulatory domain is the RNA 5'-triphosphate sensor of RIG-I. Mol Cell. (2008) 29:169-79. doi: 10.1016/j.molcel.2007.10.032

67. Hornung V, Ellegast J, Kim S, Brzózka K, Jung A, Kato H, et al. 5'Triphosphate RNA is the ligand for RIG-I. Science. (2006) 314:9947. doi: $10.1126 /$ science. 1132505

68. Pichlmair A, Schulz O, Tan CP, Naslund TI, Liljestrom P, Weber F, et al. RIG-I-mediated antiviral responses to single-stranded RNA bearing 5'Phosphates. Science. (2006) 314:997-1001. doi: 10.1126/science.1132998

69. Takahasi K, Yoneyama M, Nishihori T, Hirai R, Kumeta H, Narita $\mathrm{R}$, et al. Nonself RNA-sensing mechanism of RIG-I helicase and activation of antiviral immune responses. Mol Cell. (2008) 29:42840. doi: 10.1016/j.molcel.2007.11.028

70. Myong S, Cui S, Cornish PV, Kirchhofer A, Gack MU, Jung JU, et al. Cytosolic viral sensor RIG-I is a 5'-Triphosphate-dependent translocase on doublestranded RNA. Science. (2009) 323:1070-4. doi: 10.1126/science.1168352

71. $\mathrm{Lu} \mathrm{C,} \mathrm{Xu} \mathrm{H,} \mathrm{Ranjith-Kumar} \mathrm{CT,} \mathrm{Brooks} \mathrm{MT,} \mathrm{Hou} \mathrm{TY,} \mathrm{Hu} \mathrm{F,}$ et al. The structural basis of 5' triphosphate double-stranded RNA recognition by RIG-I C-terminal domain. Structure. (2010) 18:1032-43. doi: 10.1016/j.str.2010.05.007

72. Rehwinkel J, Tan CP, Goubau D, Schulz O, Pichlmair A, Bier K, et al. RIG-I detects viral genomic RNA during negative-strand RNA virus infection. Cell. (2010) 140:397-408. doi: 10.1016/j.cell.2010.01.020

73. Wang Y, Ludwig J, Schuberth C, Goldeck M, Schlee M, Li H, et al. Structural and functional insights into 5'-ppp RNA pattern recognition by the innate immune receptor RIG-I. Nat Struct Mol Biol. (2010) 17:7817. doi: $10.1038 / \mathrm{nsmb} .1863$

74. Vela A, Fedorova O, Ding SC, Pyle AM. The thermodynamic basis for viral RNA detection by the RIG-I innate immune sensor. J Biol Chem. (2012) 287:42564-73. doi: 10.1074/jbc.M112.385146

75. Anchisi S, Guerra J, Garcin D. RIG-I ATPase activity and discrimination of self-RNA versus non-self-RNA. MBio. (2015) 6:e02349-14. doi: 10.1128/MBIO.02349-14

76. Kato H, Takeuchi O, Mikamo-Satoh E, Hirai R, Kawai T, Matsushita K, et al. Length-dependent recognition of doublestranded ribonucleic acids by retinoic acid - inducible gene-I and melanoma differentiation - associated gene 5. J Exp Med. (2008) 205:1601-10. doi: 10.1084/jem.20080091

77. Pichlmair A, Schulz O, Tan C-P, Rehwinkel J, Kato H, Takeuchi O, et al. Activation of MDA5 requires higher-order RNA structures generated during virus infection. J Virol. (2009) 83:10761-9. doi: 10.1128/JVI.00770-09

78. Feng Q, Hato SV, Langereis MA, Zoll J, Virgen-Slane R, Peisley A, et al. MDA5 detects the double-stranded RNA replicative form in picornavirusinfected cells. Cell Rep. (2012) 2:1187-96. doi: 10.1016/j.celrep.2012.10.005

79. Triantafilou K, Vakakis E, Kar S, Richer E, Evans GL, Triantafilou M. Visualisation of direct interaction of MDA5 and the dsRNA replicative intermediate form of positive strand RNA viruses. J Cell Sci. (2012) 125:47619. doi: $10.1242 /$ jcs. 103887

80. Kolakofsky D, Kowalinski E, Cusack S. A structure-based model of RIG-I activation. RNA. (2012) 18:2118-27. doi: 10.1261/rna.035949.112

81. Luo D. Toward a crystal-clear view of the viral RNA sensing and response by RIG-I-like receptors. RNA Biol. (2014) 11:25-32. doi: 10.4161/rna. 27717

82. Reikine S, Nguyen JB, Modis Y. Pattern recognition and signaling mechanisms of RIG-I and MDA5. Front Immunol. (2014) 5:342. doi: 10.3389/fimmu.2014.00342

83. Bruns AM, Horvath CM. Antiviral RNA recognition and assembly by RLR family innate immune sensors. Cytokine Growth Factor Rev. (2014) 25:50712. doi: 10.1016/J.CYTOGFR.2014.07.006

84. Chiang C, Gack MU. Post-translational control of intracellular pathogen sensing pathways. Trends Immunol. (2017) 38:3952. doi: 10.1016/J.IT.2016.10.008

85. Gee P, Chua PK, Gevorkyan J, Klumpp K, Najera I, Swinney DC, et al. Essential role of the N-terminal domain in the regulation of RIG-I ATPase activity. J Biol Chem. (2008) 283:9488-96. doi: 10.1074/jbc.M706777200

86. Kowalinski E, Lunardi T, McCarthy AA, Louber J, Brunel J, Grigorov $B$, et al. Structural basis for the activation of innate immune pattern-recognition receptor RIG-I by viral RNA. Cell. (2011) 147:423-35. doi: 10.1016/j.cell.2011.09.039

87. Feng M, Ding Z, Xu L, Kong L, Wang W, Jiao S, et al. Structural and biochemical studies of RIG-I antiviral signaling. Protein Cell. (2013) 4:14254. doi: 10.1007/s13238-012-2088-4

88. Nistal-Villán E, Gack MU, Martínez-Delgado G, Maharaj NP, Inn K-S, Yang $\mathrm{H}$, et al. Negative role of RIG-I serine 8 phosphorylation in the regulation of interferon-beta production. J Biol Chem. (2010) 285:2025261. doi: 10.1074/jbc.M109.089912

89. Maharaj NP, Wies E, Stoll A, Gack MU. Conventional protein kinase C- $\alpha$ $(\mathrm{PKC}-\alpha)$ and PKC- $\beta$ negatively regulate RIG-I antiviral signal transduction. J Virol. (2012) 86:1358-71. doi: 10.1128/JVI.06543-11

90. Sun Z, Ren H, Liu Y, Teeling JL, Gu J. Phosphorylation of RIG-I by casein kinase II inhibits its antiviral response. J Virol. (2011) 85:103647. doi: 10.1128/JVI.01734-10

91. Takashima K, Oshiumi H, Takaki H, Matsumoto M, Seya T. RIOK3mediated phosphorylation of MDA5 interferes with its assembly and attenuates the innate immune response. Cell Rep. (2015) 11:192200. doi: 10.1016/j.celrep.2015.03.027

92. Wies E, Wang MK, Maharaj NP, Chen K, Zhou S, Finberg RW, et al. Dephosphorylation of the RNA sensors RIG-I and MDA5 by the phosphatase PP1 is essential for innate immune signaling. Immunity. (2013) 38:43749. doi: 10.1016/j.immuni.2012.11.018

93. Davis ME, Wang MK, Rennick LJ, Full F, Gableske S, Mesman AW, et al. Antagonism of the phosphatase PP1 by the measles virus $\mathrm{V}$ protein is required for innate immune escape of MDA5. Cell Host Microbe. (2014) 16:19-30. doi: 10.1016/J.CHOM.2014.06.007 
94. Choi SJ, Lee H-C, Kim J-H, Park SY, Kim T-H, Lee W-K, et al. HDAC6 regulates cellular viral RNA sensing by deacetylation of RIG-I. EMBO J. (2016) 35:429-42. doi: 10.15252/embj.201592586

95. Hilbert M, Karow AR, Klostermeier D. The mechanism of ATP-dependent RNA unwinding by DEAD box proteins. Biol Chem. (2009) 390:123750. doi: 10.1515/BC.2009.135

96. Gack MU. Mechanisms of RIG-I-like receptor activation and manipulation by viral pathogens. J Virol. (2014) 88:5213-6. doi: 10.1128/JVI.03370-13

97. Weber F. The catcher in the RIG-I. Cytokine. (2015) 76:3841. doi: 10.1016/J.CYTO.2015.07.002

98. Yoneyama M, Onomoto K, Jogi M, Akaboshi T, Fujita T. Viral RNA detection by RIG-I-like receptors. Curr Opin Immunol. (2015) 32:4853. doi: 10.1016/J.COI.2014.12.012

99. Berke IC, Modis Y. MDA5 cooperatively forms dimers and ATP-sensitive filaments upon binding double-stranded RNA. EMBO J. (2012) 31:171426. doi: 10.1038/emboj.2012.19

100. Oshiumi H, Matsumoto M, Hatakeyama S, Seya T. Riplet/RNF135, a RING finger protein, ubiquitinates RIG-I to promote interferon-beta induction during the early phase of viral infection. J Biol Chem. (2009) 284:80717. doi: 10.1074/jbc.M804259200

101. Gao D, Yang Y-K, Wang R-P, Zhou X, Diao F-C, Li M-D, et al. REUL is a novel E3 ubiquitin ligase and stimulator of retinoic-acid-inducible gene-I. PLoS ONE. (2009) 4:e5760. doi: 10.1371/journal.pone.0005760

102. Oshiumi H, Miyashita $M$, Matsumoto $M$, Seya $T$. A distinct role of Riplet-mediated K63-Linked polyubiquitination of the RIG-I repressor domain in human antiviral innate immune responses. PLoS Pathog. (2013) 9:e1003533. doi: 10.1371/journal.ppat.1003533

103. Cadena C, Ahmad S, Xavier A, Willemsen J, Park S, Park JW, et al. Ubiquitindependent and -independent roles of E3 ligase RIPLET in innate immunity. Cell. (2019) 0:1187-200.e16. doi: 10.1016/j.cell.2019.03.017

104. Gack MU, Shin YC, Joo C-H, Urano T, Liang C, Sun L, et al. TRIM25 RINGfinger E3 ubiquitin ligase is essential for RIG-I-mediated antiviral activity. Nature. (2007) 446:916-20. doi: 10.1038/nature05732

105. Wang P, Arjona A, Zhang Y, Sultana H, Dai J, Yang L, et al. Caspase-12 controls West Nile virus infection via the viral RNA receptor RIG-I. Nat Immunol. (2010) 11:912-9. doi: 10.1038/ni.1933

106. Lin H, Jiang M, Liu L, Yang Z, Ma Z, Liu S, et al. The long noncoding RNA Lnczc3h7a promotes a TRIM25-mediated RIG-I antiviral innate immune response. Nat Immunol. (2019) 20:812-23. doi: 10.1038/s41590-019-0379-0

107. Shi Y, Yuan B, Zhu W, Zhang R, Li L, Hao X, et al. Ube2D3 and Ube2N are essential for RIG-I-mediated MAVS aggregation in antiviral innate immunity. Nat Commun. (2017) 8:15138. doi: 10.1038/ncomms15138

108. Liu Z, Wu C, Pan Y, Liu H, Wang X, Yang Y, et al. NDR2 promotes the antiviral immune response via facilitating TRIM25mediated RIG-I activation in macrophages. Sci Adv. (2019) 5:eaav0163. doi: 10.1126/sciadv.aav0163

109. Pauli E-K, Chan YK, Davis ME, Gableske S, Wang MK, Feister $\mathrm{KF}$, et al. The ubiquitin-specific protease USP15 promotes RIG-Imediated antiviral signaling by deubiquitylating TRIM25. Sci Signal. (2014) 7:ra3. doi: 10.1126/scisignal.2004577

110. Liu HM, Loo Y-M, Horner SM, Zornetzer GA, Katze MG, Gale M. The mitochondrial targeting chaperone $14-3-3 \varepsilon$ regulates a RIG-I translocon that mediates membrane association and innate antiviral immunity. Cell Host Microbe. (2012) 11:528-37. doi: 10.1016/j.chom.2012.04.006

111. Yan J, Li Q, Mao A-P, Hu M-M, Shu H-B. TRIM4 modulates type I interferon induction and cellular antiviral response by targeting RIG-I for K63-linked ubiquitination. J Mol Cell Biol. (2014) 6:154-63. doi: 10.1093/jmcb/mju005

112. Sanchez JG, Chiang JJ, Sparrer KMJ, Alam SL, Chi M, Roganowicz MD, et al. Mechanism of TRIM25 catalytic activation in the antiviral RIG-I pathway. Cell Rep. (2016) 16:1315-25. doi: 10.1016/J.CELREP.2016.06.070

113. Gack MU, Albrecht RA, Urano T, Inn K-S, Huang I-C, Carnero E, et al. Influenza A virus NS1 targets the ubiquitin ligase TRIM25 to evade recognition by the host viral RNA sensor RIG-I. Cell Host Microbe. (2009) 5:439-49. doi: 10.1016/j.chom.2009.04.006

114. Rajsbaum R, Albrecht RA, Wang MK, Maharaj NP, Versteeg GA, NistalVillán E, et al. Species-specific inhibition of RIG-I ubiquitination and IFN induction by the influenza A virus NS1 protein. PLoS Pathog. (2012) 8:e1003059. doi: 10.1371/journal.ppat.1003059
115. Chiang C, Pauli E-K, Biryukov J, Feister KF, Meng M, White EA, et al. The human papillomavirus E6 oncoprotein targets USP15 and TRIM25 to suppress RIG-I-mediated innate immune signaling. J Virol. (2018) 92:e01737-17. doi: 10.1128/JVI.01737-17

116. Koliopoulos MG, Lethier M, van der Veen AG, Haubrich K, Hennig J, Kowalinski E, et al. Molecular mechanism of influenza A NS1mediated TRIM25 recognition and inhibition. Nat Commun. (2018) 9:1820. doi: 10.1038/s41467-018-04214-8

117. Chen S-T, Chen L, Lin DS-C, Chen S-Y, Tsao Y-P, Guo H, et al. NLRP12 regulates anti-viral RIG-I activation via interaction with TRIM25. Cell Host Microbe. (2019) 25:602-16.e7. doi: 10.1016/j.chom.2019.02.013

118. Zeng W, Sun L, Jiang X, Chen X, Hou F, Adhikari A, et al. Reconstitution of the RIG-I pathway reveals a signaling role of unanchored polyubiquitin chains in innate immunity. Cell. (2010) 141:315-30. doi: 10.1016/j.cell.2010.03.029

119. Maelfait J, Beyaert R. Emerging role of ubiquitination in antiviral RIG-I signaling. Microbiol Mol Biol Rev. (2012) 76:33-45. doi: 10.1128/MMBR.05012-11

120. Sun X, Xian H, Tian S, Sun T, Qin Y, Zhang S, et al. A hierarchical mechanism of RIG-I ubiquitination provides sensitivity, robustness and synergy in antiviral immune responses. Sci Rep. (2016) 6:29263. doi: 10.1038/srep29263

121. Xian H, Xie W, Yang S, Liu Q, Xia X, Jin S, et al. Stratified ubiquitination of RIG-I creates robust immune response and induces selective gene expression. Sci Adv. (2017) 3:e1701764. doi: 10.1126/sciadv.1701764

122. Oshiumi $\mathrm{H}$, Matsumoto $\mathrm{M}$, Seya T. Ubiquitin-mediated modulation of the cytoplasmic viral RNA sensor RIG-I. J Biochem. (2012) 151:511. doi: $10.1093 / \mathrm{jb} / \mathrm{mvr} 111$

123. Zhao C, Jia M, Song H, Yu Z, Wang W, Li Q, et al. The E3 ubiquitin ligase TRIM40 attenuates antiviral immune responses by targeting MDA5 and RIG-I. Cell Rep. (2017) 21:1613-23. doi: 10.1016/J.CELREP.2017.10.020

124. Okamoto M, Kouwaki T, Fukushima Y, Oshiumi H. Regulation of RIGI activation by K63-linked polyubiquitination. Front Immunol. (2017) 8:1942. doi: 10.3389/fimmu.2017.01942

125. Lian H, Zang R, Wei J, Ye W, Hu M-M, Chen Y-D, et al. The zincfinger protein $\mathrm{ZCCHC} 3$ binds RNA and facilitates viral RNA sensing and activation of the RIG-I-like receptors. Immunity. (2018) 49:43848.e5. doi: 10.1016/j.immuni.2018.08.014

126. Zhang H-L, Ye H-Q, Liu S-Q, Deng C-L, Li X-D, Shi P-Y, et al. West Nile virus NS1 antagonizes interferon beta production by targeting RIG-I and MDA5. J Virol. (2017) 91:e02396-16. doi: 10.1128/JVI.02396-16

127. Lang $\mathrm{X}$, Tang $\mathrm{T}$, Jin $\mathrm{T}$, Ding C, Zhou R, Jiang W. TRIM65-catalized ubiquitination is essential for MDA5-mediated antiviral innate immunity. J Exp Med. (2017) 214:459-73. doi: 10.1084/jem.20160592

128. Peisley A, Wu B, Xu H, Chen ZJ, Hur S. Structural basis for ubiquitinmediated antiviral signal activation by RIG-I. Nature. (2014) 509:1104. doi: 10.1038/NATURE13140

129. Tang ED, Wang C-Y. MAVS self-association mediates antiviral innate immune signaling. J Virol. (2009) 83:3420-8. doi: 10.1128/JVI.02623-08

130. Hou F, Sun L, Zheng H, Skaug B, Jiang QX, Chen ZJ. MAVS forms functional prion-like aggregates to activate and propagate antiviral innate immune response. Cell. (2011) 146:448-61. doi: 10.1016/j.cell.2011.06.041

131. Xu H, He X, Zheng H, Huang LJ, Hou F, Yu Z, et al. Structural basis for the prion-like MAVS filaments in antiviral innate immunity. Elife. (2014) 3:e1489. doi: 10.7554/eLife.01489

132. He L, Lührs T, Ritter C. Solid-state NMR resonance assignments of the filament-forming CARD domain of the innate immunity signaling protein MAVS. Biomol NMR Assign. (2015) 9:223-7. doi: 10.1007/s12104-014-9579-6

133. Wu B, Hur S. How RIG-I like receptors activate MAVS. Curr Opin Virol. (2015) 12:91-8. doi: 10.1016/j.coviro.2015.04.004

134. Luo D, Kohlway A, Vela A, Pyle AM. Visualizing the determinants of viral RNA recognition by innate immune sensor RIG-I. Structure. (2012) 20:1983-8. doi: 10.1016/j.str.2012.08.029

135. Kohlway A, Luo D, Rawling DC, Ding SC, Pyle AM. Defining the functional determinants for RNA surveillance by RIG-I. EMBO Rep. (2013) 14:7729. doi: 10.1038/embor.2013.108

136. Linehan MM, Dickey TH, Molinari ES, Fitzgerald ME, Potapova O, Iwasaki A, et al. A minimal RNA ligand for potent RIG-I activation in living mice. Sci Adv. (2018) 4:e1701854. doi: 10.1126/sciadv.1701854 
137. Peisley A, Lin C, Wu B, Orme-Johnson M, Liu M, Walz T, et al. Cooperative assembly and dynamic disassembly of MDA5 filaments for viral dsRNA recognition. Proc Natl Acad Sci USA. (2011) 108:210105. doi: 10.1073/pnas.1113651108

138. Berke IC, Yu X, Modis Y, Egelman EH. MDA5 assembles into a polar helical filament on dsRNA. Proc Natl Acad Sci USA. (2012) 109:1843741. doi: $10.1073 /$ pnas. 1212186109

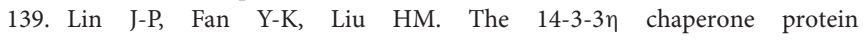
promotes antiviral innate immunity via facilitating MDA5 oligomerization and intracellular redistribution. PLoS Pathog. (2019) 15:e1007582. doi: 10.1371/journal.ppat.1007582

140. Zheng Y, Gao C. E3 ubiquitin ligases, the powerful modulator of innate antiviral immunity. Cell Immunol. (2019) 340:103915. doi: 10.1016/J.CELLIMM.2019.04.003

141. Patel JR, Jain A, Chou Y, Baum A, Ha T, García-Sastre A. ATPasedriven oligomerization of RIG-I on RNA allows optimal activation of type-I interferon. EMBO Rep. (2013) 14:780-7. doi: 10.1038/embor. 2013.102

142. Peisley A, Wu B, Yao H, Walz T, Hur S. RIG-I forms signaling-competent filaments in an ATP-dependent, ubiquitin-independent manner. Mol Cell. (2013) 51:573-83. doi: 10.1016/J.MOLCEL.2013.07.024

143. Binder M, Eberle F, Seitz S, Mücke N, Hüber CM, Kiani N, et al. Molecular mechanism of signal perception and integration by the innate immune sensor retinoic acid-inducible gene-I (RIG-I). J Biol Chem. (2011) 286:27278-87. doi: 10.1074/jbc.M111.256974

144. Devarkar SC, Schweibenz B, Wang C, Marcotrigiano J, Patel SS. RIGI uses an ATPase-powered translocation-throttling mechanism for kinetic proofreading of RNAs and oligomerization. Mol Cell. (2018) 72:35568.e4. doi: 10.1016/j.molcel.2018.08.021

145. Sohn J, Hur S. Filament assemblies in foreign nucleic acid sensors. Curr Opin Struct Biol. (2016) 37:134-44. doi: 10.1016/j.sbi.2016.01.011

146. Kawai T, Takahashi K, Sato S, Coban C, Kumar H, Kato H, et al. IPS-1, an adaptor triggering RIG-I- and Mda5-mediated type I interferon induction. Nat Immunol. (2005) 6:981-8. doi: 10.1038/ni1243

147. Xu L-G, Wang Y-Y, Han K-J, Li L-Y, Zhai Z, Shu H-B. VISA is an adapter protein required for virus-triggered IFN- $\beta$ signaling. Mol Cell. (2005) 19:727-40. doi: 10.1016/J.MOLCEL.2005.08.014

148. Seth RB, Sun L, Ea C-K, Chen ZJ. Identification and characterization of MAVS, a mitochondrial antiviral signaling protein that activates NF-KB and IRF3. Cell. (2005) 122:669-82. doi: 10.1016/J.CELL.2005. 08.012

149. Hu J, Nistal-Villán E, Voho A, Ganee A, Kumar M, Ding Y, et al. A common polymorphism in the caspase recruitment domain of RIG-I modifies the innate immune response of human dendritic cells. J Immunol. (2010) 185:424-32. doi: 10.4049/jimmunol.0903291

150. Marcus PI, Sekellick MJ. Defective interfering particles with covalently linked [+/-]RNA induce interferon. Nature. (1977) 266:815-9. doi: 10.1038/266815a0

151. Ferrage F, Dutta K, Nistal-Villán E, Patel JR, Sánchez-Aparicio MT, De Ioannes $\mathrm{P}$, et al. Structure and dynamics of the second CARD of human RIGI provide mechanistic insights into regulation of RIG-I activation. Structure. (2012) 20:2048-61. doi: 10.1016/j.str.2012.09.003

152. Takeuchi O, Akira S. Pattern recognition receptors and inflammation. Cell. (2010) 140:805-20. doi: 10.1016/j.cell.2010.01.022

153. Arnoult D, Soares F, Tattoli I, Girardin SE. Mitochondria in innate immunity. EMBO Rep. (2011) 12:901-10. doi: 10.1038/EMBOR.2011.157

154. Schröder M, Baran M, Bowie AG. Viral targeting of DEAD box protein 3 reveals its role in TBK1/IKKepsilon-mediated IRF activation. EMBO J. (2008) 27:2147-57. doi: 10.1038/emboj.2008.143

155. Ng CT, Sullivan BM, Teijaro JR, Lee AM, Welch M, Rice S, et al. Blockade of interferon beta, but not interferon alpha, signaling controls persistent viral infection. Cell Host Microbe. (2015) 17:653-61. doi: 10.1016/j.chom.2015.04.005

156. Tsau JS, Huang X, Lai C-Y, Hedrick SM. The effects of dendritic cell hypersensitivity on persistent viral infection. J Immunol. (2018) 200:133546. doi: 10.4049/jimmunol.1601870

157. Camp JV, Jonsson CB. A role for neutrophils in viral respiratory disease. Front Immunol. (2017) 8:550. doi: 10.3389/fimmu.2017.00550
158. Gilliet M, Cao W, Liu Y-J. Plasmacytoid dendritic cells: sensing nucleic acids in viral infection and autoimmune diseases. Nat Rev Immunol. (2008) 8:594-606. doi: 10.1038/nri2358

159. Kong L, Sun L, Zhang H, Liu Q, Liu Y, Qin L, et al. An essential role for RIG-I in toll-like receptor-stimulated phagocytosis. Cell Host Microbe. (2009) 6:150-61. doi: 10.1016/j.chom.2009.06.008

160. Ma H, Han P, Ye W, Chen H, Zheng X, Cheng L, et al. The long noncoding RNA NEAT1 exerts antihantaviral effects by acting as positive feedback for RIG-I signaling. J Virol. (2017) 91:e02250-16. doi: 10.1128/JVI. 02250-16

161. Marie I, Durbin JE, Levy D. Differential viral induction of distinct interferonalpha genes by positive feedback through interferon regulatory factor-7. EMBO J. (1998) 17:6660-9. doi: 10.1093/emboj/17.22.6660

162. Haller O, Kochs G, Weber F. The interferon response circuit: Induction and suppression by pathogenic viruses. Virology. (2006) 344:119-30. doi: 10.1016/j.virol.2005.09.024

163. Hui KPY, Lee SMY, Cheung CY, Mao H, Lai AKW, Chan RWY, et al. H5N1 influenza virus-induced mediators upregulate RIG-I in uninfected cells by paracrine effects contributing to amplified cytokine cascades. J Infect Dis. (2011) 204:1866-78. doi: 10.1093/infdis/jir665

164. Shaw AE, Hughes J, Gu Q, Behdenna A, Singer JB, Dennis T, et al. Fundamental properties of the mammalian innate immune system revealed by multispecies comparison of type I interferon responses. PLoS Biol. (2017) 15:e2004086. doi: 10.1371/journal.pbio.2004086

165. Cui X-F, Imaizumi T, Yoshida H, Borden EC, Satoh K. Retinoic acidinducible gene-I is induced by interferon- $\gamma$ and regulates the expression of interferon- $\gamma$ stimulated gene 15 in MCF-7 cells. Biochem Cell Biol. (2004) 82:401-5. doi: 10.1139/o04-041

166. Imaizumi $\mathrm{T}$, Yagihashi $\mathrm{N}$, Hatakeyama $\mathrm{M}$, Yamashita $\mathrm{K}$, Ishikawa $\mathrm{A}$, Taima $\mathrm{K}$, et al. Expression of retinoic acid-inducible gene-I in vascular smooth muscle cells stimulated with interferon- $\gamma$. Life Sci. (2004) 75:117180. doi: 10.1016/J.LFS.2004.01.030

167. Yount JS, Moran TM, López CB. Cytokine-independent upregulation of MDA5 in viral infection. J Virol. (2007) 81:7316-9. doi: 10.1128/JVI.00545-07

168. Schmidt A, Schwerd T, Hamm W, Hellmuth JC, Cui S, Wenzel M, et al. 5'-triphosphate RNA requires base-paired structures to activate antiviral signaling via RIG-I. Proc Natl Acad Sci USA. (2009) 106:1206772. doi: 10.1073/pnas.0900971106

169. Marq J-B, Kolakofsky D, Garcin D. Unpaired 5' ppp-nucleotides, as found in arenavirus double-stranded RNA panhandles, are not recognized by RIG-I. J Biol Chem. (2010) 285:18208-16. doi: 10.1074/jbc.M109.0 89425

170. Schlee M, Roth A, Hornung V, Hagmann CA, Wimmenauer V, Barchet W, et al. Recognition of 5' triphosphate by RIG-I helicase requires short blunt double-stranded RNA as contained in panhandle of negative-strand virus. Immunity. (2009) 31:25-34. doi: 10.1016/j.immuni.2009.05.008

171. Marq J-B, Hausmann S, Veillard N, Kolakofsky D, Garcin D. Short double-stranded RNAs with an overhanging 5' ppp-nucleotide, as found in arenavirus genomes, act as RIG-I decoys. J Biol Chem. (2011) 286:610816. doi: $10.1074 /$ jbc.M110.186262

172. Lu C, Ranjith-Kumar CT, Hao L, Kao CC, Li P. Crystal structure of RIGI C-terminal domain bound to blunt-ended double-strand RNA without 5' triphosphate. Nucleic Acids Res. (2011) 39:1565-75. doi: 10.1093/nar/gkq974

173. Goubau D, Schlee M, Deddouche S, Pruijssers AJ, Zillinger T, Goldeck $\mathrm{M}$, et al. Antiviral immunity via RIG-I-mediated recognition of RNA bearing 5'-diphosphates. Nature. (2014) 514:372-5. doi: 10.1038/nature 13590

174. Kumar A, Satpati P. Energetics of preferential binding of retinoic acid-inducible gene-I to double-stranded viral RNAs with 5' Tri/Diphosphate over 5' Monophosphate. ACS Omega. (2018) 3:378695. doi: 10.1021/acsomega.7b02019

175. Ren X, Linehan MM, Iwasaki A, Pyle AM. RIG-I selectively discriminates against 5'-monophosphate RNA. Cell Rep. (2019) 26:2019-27.e4. doi: 10.1016/j.celrep.2019.01.107

176. Rawling DC, Fitzgerald ME, Pyle AM. Establishing the role of ATP for the function of the RIG-I innate immune sensor. Elife. (2015) 4:e09391. doi: 10.7554/eLife.09391 
177. Jiao X, Chang JH, Kilic T, Tong L, Kiledjian M. A mammalian premRNA 5' end capping quality control mechanism and an unexpected link of capping to pre-mRNA processing. Mol Cell. (2013) 50:10415. doi: 10.1016/j.molcel.2013.02.017

178. Court DL, Gan J, Liang Y-H, Shaw GX, Tropea JE, Costantino N, et al. RNase III: genetics and function; structure and mechanism. Annu Rev Genet. (2013) 47:405-31. doi: 10.1146/annurev-genet-110711-155618

179. Malathi K, Saito T, Crochet N, Barton DJ, Gale M, Silverman RH, et al. RNase $\mathrm{L}$ releases a small RNA from HCV RNA that refolds into a potent PAMP. RNA. (2010) 16:2108-19. doi: 10.1261/rna.2244210

180. Wiatrek DM, Candela ME, Sedmík J, Oppelt J, Keegan LP, O’Connell MA. Activation of innate immunity by mitochondrial dsRNA in mouse cells lacking p53 protein. RNA. (2019) 25:713-26. doi: 10.1261/rna.069625.118

181. Chakrabarti A, Jha BK, Silverman RH. New insights into the role of RNase L in innate immunity. J Interferon Cytokine Res. (2011) 31:4957. doi: 10.1089/jir.2010.0120

182. Li X, Lu C, Stewart M, Xu H, Strong RK, Igumenova T, et al. Structural basis of double-stranded RNA recognition by the RIG-I like receptor MDA5. Arch Biochem Biophys. (2009) 488:23-33. doi: 10.1016/J.ABB.2009.06.008

183. Li X, Ranjith-Kumar CT, Brooks MT, Dharmaiah S, Herr AB, Kao C, et al. The RIG-I-like receptor LGP2 recognizes the termini of doublestranded RNA. J Biol Chem. (2009) 284:13881-91. doi: 10.1074/jbc.M9008 18200

184. Sarkar D, Desalle R, Fisher PB, Goodman M. Evolution of MDA-5/RIGI-dependent innate immunity: independent evolution by domain grafting. Proc Natl Acad Sci USA. (2008) 105:17040-5. doi: 10.1073/pnas.0804956105

185. Saito T, Hirai R, Loo Y-M, Owen D, Johnson CL, Sinha SC, et al. Regulation of innate antiviral defenses through a shared repressor domain in RIG-I and LGP2. Proc Natl Acad Sci USA. (2007) 104:5827. doi: 10.1073/pnas.0606699104

186. Luthra P, Sun D, Silverman RH, He B. Activation of IFN- $\beta$ expression by a viral mRNA through RNase L and MDA5. Proc Natl Acad Sci USA. (2011) 108:2118-23. doi: 10.1073/pnas.1012409108

187. Chow KT, Gale M, Loo Y-M. RIG-I and Other RNA Sensors in Antiviral Immunity. Annu Rev Immunol. (2018) 36:66794. doi: 10.1146/annurev-immunol-042617-053309

188. Chiu Y-H, Macmillan JB, Chen ZJ. RNA polymerase III detects cytosolic DNA and induces type I interferons through the RIG-I pathway. Cell. (2009) 138:576-91. doi: 10.1016/j.cell.2009.06.015

189. Ablasser A, Bauernfeind F, Hartmann G, Latz E, Fitzgerald KA, Hornung V. RIG-I-dependent sensing of poly(dA:dT) through the induction of an RNA polymerase III-transcribed RNA intermediate. Nat Immunol. (2009) 10:1065-72. doi: 10.1038/ni.1779

190. Chiang C, Beljanski V, Yin K, Olagnier D, Ben Yebdri F, Steel $\mathrm{C}$, et al. Sequence-specific modifications enhance the broad-spectrum antiviral response activated by RIG-I agonists. J Virol. (2015) 89:801125. doi: 10.1128/JVI.00845-15

191. Ho V, Yong HY, Chevrier M, Narang V, Lum J, Toh Y-X, et al. RIG-I activation by a designer short RNA ligand protects human immune cells against dengue virus infection without causing cytotoxicity. J Virol. (2019) 93:e00102-19. doi: 10.1128/JVI.00102-19

192. Xu J, Mercado-López X, Grier JT, Kim W, Chun LF, Irvine EB, et al. Identification of a natural viral RNA motif that optimizes sensing of viral RNA by RIG-I. MBio. (2015) 6:e01265-15. doi: 10.1128/mBio.01265-15

193. Runge S, Sparrer KMJ, Lässig C, Hembach K, Baum A, García-Sastre A, et al. In vivo ligands of MDA5 and RIG-I in measles virus-infected cells. PLoS Pathog. (2014) 10:e1004081. doi: 10.1371/journal.ppat.1004081

194. Davis WG, Bowzard JB, Sharma SD, Wiens ME, Ranjan P, Gangappa $\mathrm{S}$, et al. The 3' untranslated regions of influenza genomic sequences are 5'PPP-independent ligands for RIG-I. PLoS ONE. (2012) 7:e32661. doi: 10.1371/journal.pone.0032661

195. Zhang Y, Dittmer DP, Mieczkowski PA, Host KM, Fusco WG, Duncan JA, et al. RIG-I detects Kaposi's sarcoma-associated herpesvirus transcripts in a RNA polymerase III-independent manner. MBio. (2018) 9:e0082318. doi: 10.1128/mBio.00823-18

196. Saito T, Owen DM, Jiang F, Marcotrigiano J, Gale M Jr. Innate immunity induced by composition-dependent RIG-I recognition of hepatitis $\mathrm{C}$ virus RNA. Nature. (2008) 454:523-7. doi: 10.1038/nature07106
197. Uzri D, Gehrke L. Nucleotide sequences and modifications that determine RIG-I/RNA binding and signaling activities. J Virol. (2009) 83:417484. doi: 10.1128/JVI.02449-08

198. Jiang M, Zhang S, Yang Z, Lin H, Zhu J, Liu L, et al. Self-recognition of an inducible host lncRNA by RIG-I feedback restricts innate immune response. Cell. (2018) 173:906-19.e13. doi: 10.1016/j.cell.2018.03.064

199. Gebhardt A, Laudenbach BT, Pichlmair A. Discrimination of self and non-self ribonucleic acids. J Interf Cytokine Res. (2017) 37:18497. doi: 10.1089/jir.2016.0092

200. Huang AS, Baltimore D. Defective viral particles and viral disease processes. Nature. (1970) 226:325-7. doi: 10.1038/226325a0

201. Huang AS. Defective interfering viruses. Annu Rev Microbiol. (1973) 27:10118. doi: 10.1146/annurev.mi.27.100173.000533

202. Leppert M, Kort L, Kolakofsky D. Further characterization of Sendai virus DI-RNAs: a model for their generation. Cell. (1977) 12:53952. doi: 10.1016/0092-8674(77)90130-1

203. Nichol ST, O’Hara PJ, Holland JJ, Perrault J. Structure and origin of a novel class of defective interfering particle of vesicular stomatitis virus. Nucleic Acids Res. (1984) 12:2775-90. doi: 10.1093/nar/12.6.2775

204. Strahle L, Marq J-B, Brini A, Hausmann S, Kolakofsky D, Garcin D. Activation of the beta interferon promoter by unnatural sendai virus infection requires RIG-I and is inhibited by viral C proteins. J Virol. (2007) 81:12227-37. doi: 10.1128/jvi.01300-07

205. Baum A, Sachidanandam R, García-Sastre A. Preference of RIG-I for short viral RNA molecules in infected cells revealed by nextgeneration sequencing. Proc Natl Acad Sci USA. (2010) 107:163038. doi: 10.1073/pnas.1005077107

206. Baum A, García-Sastre A. Differential recognition of viral RNA by RIG-I. Virulence. (2011) 2:166-9. doi: 10.4161/viru.2.2.15481

207. Ho T-H, Kew C, Lui P-Y, Chan C-P, Satoh T, Akira S, et al. PACT- and RIG-I-dependent activation of type I interferon production by a defective interfering RNA derived from measles virus vaccine. J Virol. (2016) 90:155768. doi: 10.1128/JVI.02161-15

208. Liu G, Lu Y, Liu Q, Zhou Y. Inhibition of ongoing influenza A virus replication reveals different mechanisms of RIG-I activation. J Virol. (2019) 93:e02066-18. doi: 10.1128/JVI.02066-18

209. Liu G, Park H-S, Pyo H-M, Liu Q, Zhou Y. Influenza A virus panhandle structure is directly involved in RIG-I activation and interferon induction. $J$ Virol. (2015) 89:6067-79. doi: 10.1128/JVI.00232-15

210. Nayak DP, Sivasubramanian N. The structure of influenza virus defective interfering (DI) RNAs and their progenitor genes. In: Palese P, Kingsbury DW editors. Genetics of Influenza Viruses. Vienna: Springer Vienna (1983). p. 255-79. doi: 10.1007/978-3-7091-8706-7_8

211. Yount JS, Gitlin L, Moran TM, López CB. MDA5 participates in the detection of paramyxovirus infection and is essential for the early activation of dendritic cells in response to sendai virus defective interfering particles. $J$ Immunol. (2008) 180:4910-8. doi: 10.4049/JIMMUNOL.180.7.4910

212. Yount JS, Kraus TA, Horvath CM, Moran TM, López CB. A novel role for viral-defective interfering particles in enhancing dendritic cell maturation. J Immunol. (2006) 177:4503-13. doi: 10.4049/JIMMUNOL.177.7.4503

213. Dimmock NJ, Easton AJ. Defective interfering influenza virus RNAs: time to reevaluate their clinical potential as broad-spectrum antivirals? J Virol. (2014) 88:5217-27. doi: 10.1128/JVI.03193-13

214. Weinberger B, Herndler-Brandstetter D, Schwanninger A, Weiskopf D, Grubeck-Loebenstein B. Biology of immune responses to vaccines in elderly persons. Clin Infect Dis. (2008) 46:1078-84. doi: 10.1086/529197

215. Chen WH, Kozlovsky BF, Effros RB, Grubeck-Loebenstein B, Edelman R, Sztein MB. Vaccination in the elderly: an immunological perspective. Trends Immunol. (2009) 30:351-9. doi: 10.1016/j.it.2009.05.002

216. Derhovanessian E, Pawelec G. Vaccination in the elderly. Microb Biotechnol. (2012) 5:226-32. doi: 10.1111/j.1751-7915.2011.00283.x

217. Ciabattini A, Nardini C, Santoro F, Garagnani P, Medaglini D. Vaccination in the elderly: the challenge of immune changes with aging. Semin Immunol. (2018) 40:83-94. doi: 10.1016/J.SMIM.2018.10.010

218. Molony RD, Nguyen JT, Kong Y, Montgomery RR, Shaw AC, Iwasaki A. Aging impairs both primary and secondary RIG-I signaling for interferon induction in human monocytes. Sci Signal. (2017) 10:eaan2392. doi: 10.1126/scisignal.aan2392 
219. Newall AT, Chen C, Wood JG, Stockwell MS. Within-season influenza vaccine waning suggests potential net benefits to delayed vaccination in older adults in the United States. Vaccine. (2018) 36:5910-5. doi: 10.1016/J.VACCINE.2018.08.007

220. Oldstone MB. Viral persistence: mechanisms and consequences. Curr Opin Microbiol. (1998) 1:436-41. doi: 10.1016/S1369-5274(98)80062-3

221. Manzoni TB, López CB. Defective (interfering) viral genomes re-explored: impact on antiviral immunity and virus persistence. Future Virol. (2018) 13:493-503. doi: 10.2217/fvl-2018-0021

222. Stauffer Thompson KA, Rempala GA, Yin J. Multiple-hit inhibition of infection by defective interfering particles. J Gen Virol. (2009) 90:88899. doi: 10.1099/vir.0.005249-0

223. Ziegler CM, Eisenhauer P, Bruce EA, Beganovic V, King BR, Weir ME, et al. A novel phosphoserine motif in the LCMV matrix protein $\mathrm{Z}$ regulates the release of infectious virus and defective interfering particles. J Gen Virol. (2016) 97:2084-9. doi: 10.1099/jgv.0.000550

224. Ziegler C, Eisenhauer P, Manuelyan I, Weir M, Bruce E, Ballif B, et al. Hostdriven phosphorylation appears to regulate the budding activity of the lassa virus matrix protein. Pathogens. (2018) 7:97. doi: 10.3390/pathogens7040097

225. Rehwinkel J, Reis e Sousa C. RIGorous detection: exposing virus through RNA sensing. Science. (2010) 327:284-6. doi: 10.1126/science.1185068

226. Rice GI, Del Toro Duany Y, Jenkinson EM, Forte GM, Anderson BH, Ariaudo G, et al. Gain-of-function mutations in IFIH1 cause a spectrum of human disease phenotypes associated with upregulated type I interferon signaling. Nat Genet. (2014) 46:503-9. doi: 10.1038/ng.2933

227. Ahmad S, Mu X, Yang F, Greenwald E, Park JW, Jacob E, et al. Breaching self-tolerance to Alu duplex RNA underlies MDA5-mediated inflammation. Cell. (2018) 172:797. doi: 10.1016/J.CELL.2017.12.016

228. Oda H, Nakagawa K, Abe J, Awaya T, Funabiki M, Hijikata A, et al. AicardiGoutières syndrome is caused by IFIH1 mutations. Am J Hum Genet. (2014) 95:121-5. doi: 10.1016/j.ajhg.2014.06.007

229. Funabiki M, Kato $H$, Miyachi $Y$, Toki $H$, Motegi $H$, Inoue $\mathrm{M}$, et al. Autoimmune disorders associated with gain of function of the intracellular sensor MDA5. Immunity. (2014) 40:199-212. doi: 10.1016/J.IMMUNI.2013.12.014

230. Schuberth-Wagner C, Ludwig J, Bruder AK, Herzner A-M, Zillinger T, Goldeck M, et al. A conserved histidine in the RNA sensor RIG-I controls immune tolerance to N1-2'O-methylated Self RNA. Immunity. (2015) 43:4151. doi: 10.1016/j.immuni.2015.06.015

231. Zheng J, Yong HY, Panutdaporn N, Liu C, Tang K, Luo D. Highresolution HDX-MS reveals distinct mechanisms of RNA recognition and activation by RIG-I and MDA5. Nucleic Acids Res. (2015) 43:121630. doi: 10.1093/nar/gku1329

232. Zheng J, Wang C, Chang MR, Devarkar SC, Schweibenz B, Crynen GC, et al. HDX-MS reveals dysregulated checkpoints that compromise discrimination against self RNA during RIG-I mediated autoimmunity. Nat Commun. (2018) 9:5366. doi: 10.1038/s41467-018-07780-z

233. Lässig C, Matheisl S, Sparrer KMJM, de Oliveira Mann CC, Moldt M, Patel JR, et al. ATP hydrolysis by the viral RNA sensor RIGI prevents unintentional recognition of self-RNA. Elife. (2015) 4:e10859. doi: 10.7554/eLife.10859

234. Nallagatla SR, Toroney R, Bevilacqua PC. A brilliant disguise for self RNA: 5 '-end and internal modifications of primary transcripts suppress elements of innate immunity. RNA Biol. (2008) 5:140-4. doi: 10.4161/rna.5.3.6839

235. Gokhale NS, Horner SM. RNA modifications go viral. PLoS Pathog. (2017) 13:e1006188. doi: 10.1371/journal.ppat.1006188

236. Durbin AF, Wang C, Marcotrigiano J, Gehrke L. RNAs containing modified nucleotides fail to trigger RIG-I conformational changes for innate immune signaling. MBio. (2016) 7:e00833-16. doi: 10.1128/mBio.00833-16

237. Oshiumi H, Mifsud EJ, Daito T. Links between recognition and degradation of cytoplasmic viral RNA in innate immune response. Rev Med Virol. (2016) 26:90-101. doi: 10.1002/rmv.1865

238. Satoh T, Kato H, Kumagai Y, Yoneyama M, Sato S, Matsushita K, et al. LGP2 is a positive regulator of RIG-I- and MDA5-mediated antiviral responses. Proc Natl Acad Sci USA. (2010) 107:1512-7. doi: 10.1073/pnas.0912986107

239. Civril F, Bennett M, Moldt M, Deimling T, Witte G, Schiesser $\mathrm{S}$, et al. The RIG-I ATPase domain structure reveals insights into ATP-dependent antiviral signalling. EMBO Rep. (2011) 12:1127-34. doi: 10.1038/embor.2011.190

240. Wilson RC, Doudna JA. Molecular mechanisms of RNA interference. Annu Rev Biophys. (2013) 42:21739. doi: 10.1146/annurev-biophys-083012-130404

241. Peach SE, York K, Hesselberth JR. Global analysis of RNA cleavage by 5'-hydroxyl RNA sequencing. Nucleic Acids Res. (2015) 43:e108. doi: 10.1093/nar/gkv536

242. Louber J, Brunel J, Uchikawa E, Cusack S, Gerlier D. Kinetic discrimination of self/non-self RNA by the ATPase activity of RIG-I and MDA5. BMC Biol. (2015) 13:54. doi: 10.1186/s12915-015-0166-9

243. Yu Q, Qu K, Modis Y. Cryo-EM structures of MDA5-dsRNA filaments at different stages of ATP hydrolysis. Mol Cell. (2018) 72:999-1012.e6. doi: 10.1016/J.MOLCEL.2018.10.012

244. Wang M, Yu F, Wu W, Zhang Y, Chang W, Ponnusamy M, et al. Circular RNAs: a novel type of non-coding RNA and their potential implications in antiviral immunity. Int J Biol Sci. (2017) 13:1497-506. doi: 10.7150/ijbs.22531

245. Chen YG, Kim MV, Chen X, Batista PJ, Aoyama S, Wilusz JE, et al. Sensing self and foreign circular RNAs by intron identity. Mol Cell. (2017) 67:22838.e5. doi: 10.1016/j.molcel.2017.05.022

246. Eckard SC, Rice GI, Fabre A, Badens C, Gray EE, Hartley JL, et al. The SKIV2L RNA exosome limits activation of the RIG-I-like receptors. Nat Immunol. (2014) 15:839-45. doi: 10.1038/ni.2948

247. Murai K, Honda M, Shirasaki T, Shimakami T, Omura H, Misu H, et al. Induction of selenoprotein $\mathrm{P}$ mRNA during hepatitis $\mathrm{C}$ virus infection inhibits RIG-I-mediated antiviral immunity. Cell Host Microbe. (2019) 25:588-601.e7. doi: 10.1016/j.chom.2019.02.015

248. Fan J, Cheng M, Chi X, Liu X, Yang W. Human long non-coding RNA LncATV promotes viral replication by restricting RIG-I-mediated innate immunity. Front. Immunol. (2019) 10:1711. doi: 10.3389/fimmu.2019.01711

249. Kim D, Kim H, Han S, Scatena M, Kim D-H, Lee JB. Immunostimulatory effects triggered by self-assembled microspheres with tandem repeats of polymerized RNA strands. Adv Healthc Mater. (2019) 8:1801395. doi: 10.1002/adhm.201801395

250. Zhao K, Du J, Peng Y, Li P, Wang S, Wang Y, et al. LINE1 contributes to autoimmunity through both RIG-I- and MDA5-mediated RNA sensing pathways. J Autoimmun. (2018) 90:105-15. doi: 10.1016/J.JAUT.2018.02.007

251. Chiang JJ, Sparrer KMJ, van Gent M, Lässig C, Huang T, Osterrieder $\mathrm{N}$, et al. Viral unmasking of cellular 5S rRNA pseudogene transcripts induces RIG-I-mediated immunity. Nat Immunol. (2018) 19:53-62. doi: 10.1038/s41590-017-0005-y

252. Khan M, Syed GH, Kim S-J, Siddiqui A. Mitochondrial dynamics and viral infections: a close nexus. Biochim Biophys Acta. (2015) 1853:282233. doi: 10.1016/j.bbamcr.2014.12.040

253. Dhir A, Dhir S, Borowski LS, Jimenez L, Teitell M, Rötig A, et al. Mitochondrial double-stranded RNA triggers antiviral signalling in humans. Nature. (2018) 560:238-42. doi: 10.1038/s41586-018-0363-0

254. Hardy M-P, Audemard É, Migneault F, Feghaly A, Brochu S, Gendron $\mathrm{P}$, et al. Apoptotic endothelial cells release small extracellular vesicles loaded with immunostimulatory viral-like RNAs. Sci Rep. (2019) 9:7203. doi: 10.1038/s41598-019-43591-y

255. Hoffmann H-H, Schneider WM, Rice CM. Interferons and viruses: an evolutionary arms race of molecular interactions. Trends Immunol. (2015) 36:124-38. doi: 10.1016/j.it.2015.01.004

256. Schulz KS, Mossman KL. Viral evasion strategies in type I IFN signaling - a summary of recent developments. Front Immunol. (2016) 7:498. doi: 10.3389/fimmu.2016.00498

257. Chan YK, Gack MU. Viral evasion of intracellular DNA and RNA sensing. Nat Rev Microbiol. (2016) 14:360-73. doi: 10.1038/nrmicro. 2016.45

258. García-Sastre A. Ten strategies of interferon evasion by viruses. Cell Host Microbe. (2017) 22:176-84. doi: 10.1016/j.chom.2017.07.012

259. Weber M, Weber F. Segmented negative-strand RNA viruses and RIGI: divide (your genome) and rule. Curr Opin Microbiol. (2014) 20:96102. doi: 10.1016/J.MIB.2014.05.002

260. Samji T. Influenza A: understanding the viral life cycle. Yale J Biol Med. (2009) 82:153-9. 
261. Liu G, Lu Y, Thulasi Raman SN, Xu F, Wu Q, Li Z, et al. Nuclear-resident RIG-I senses viral replication inducing antiviral immunity. Nat Commun. (2018) 9:3199. doi: 10.1038/s41467-018-05745-w

262. Habjan M, Andersson I, Klingström J, Schümann M, Martin A, Zimmermann P, et al. Processing of genome $5^{\prime}$ termini as a strategy of negative-strand RNA viruses to avoid RIG-I-dependent interferon induction. PLoS ONE. (2008) 3:e2032. doi: 10.1371/journal.pone.0002032

263. Ingle H, Kumar S, Raut AA, Mishra A, Kulkarni DD, Kameyama T, et al. The microRNA miR-485 targets host and influenza virus transcripts to regulate antiviral immunity and restrict viral replication. Sci Signal. (2015) 8:ra126. doi: 10.1126/scisignal.aab3183

264. Yoshida A, Kawabata R, Honda T, Sakai K, Ami Y, Sakaguchi T, et al. A single amino acid substitution within the paramyxovirus sendai virus nucleoprotein is a critical determinant for production of interferon-betainducing copyback-type defective interfering genomes. J Virol. (2018) 92:e02094-17. doi: 10.1128/JVI.02094-17

265. Te Velthuis AJW, Long JC, Bauer DLV, Fan RLY, Yen H-L, Sharps J, et al. Mini viral RNAs act as innate immune agonists during influenza virus infection. Nat Microbiol. (2018) 3:1234-42. doi: 10.1038/s41564-0180240-5

266. Nikonov A, Mölder T, Sikut R, Kiiver K, Männik A, Toots U, et al. RIG-I and MDA-5 detection of viral RNA-dependent RNA polymerase activity restricts positive-strand RNA virus replication. PLoS Pathog. (2013) 9:e1003610. doi: 10.1371/journal.ppat.1003610

267. King BR, Samacoits A, Eisenhauer PL, Ziegler CM, Bruce EA, Zenklusen D, et al. Visualization of arenavirus RNA species in individual cells by singlemolecule fluorescence in situ hybridization (smFISH) suggests a model of cyclical infection and clearance during persistence. J Virol. (2018) 92:e0224117. doi: 10.1128/JVI.02241-17

268. Hastie KM, Kimberlin CR, Zandonatti MA, MacRae IJ, Saphire EO. Structure of the Lassa virus nucleoprotein reveals a dsRNA-specific 3' to 5' exonuclease activity essential for immune suppression. Proc Natl Acad Sci USA. (2011) 108:2396-401. doi: 10.1073/pnas.1016404108

269. Huang Q, Shao J, Lan S, Zhou Y, Xing J, Dong C, et al. In vitro and in vivo characterizations of pichinde viral nucleoprotein exoribonuclease functions. J Virol. (2015) 89:6595-607. doi: 10.1128/JVI.00009-15

270. Ma Y, Wu L, Shaw N, Gao Y, Wang J, Sun Y, et al. Structural basis and functional analysis of the SARS coronavirus nsp14-nsp10 complex. Proc Natl Acad Sci USA. (2015) 112:9436-41. doi: 10.1073/pnas.1508686112

271. Durzynska I, Sauerwald M, Karl N, Madhugiri R, Ziebuhr J. Characterization of a bafinivirus exoribonuclease activity. J Gen Virol. (2018) 99:125360. doi: $10.1099 /$ jgv. 0.001120

272. Chiang JJ, Davis ME, Gack MU. Regulation of RIG-I-like receptor signaling by host and viral proteins. Cytokine Growth Factor Rev. (2014) 25:491505. doi: 10.1016/J.CYTOGFR.2014.06.005

273. Ling Z, Tran KC, Teng MN. Human respiratory syncytial virus non-structural protein NS2 antagonizes the activation of beta interferon transcription by interacting with RIG-I. J Virol. (2009) 83:3734-42. doi: 10.1128/JVI.02434-08

274. Xing J, Ly H, Liang Y. The Z proteins of pathogenic but not non-pathogenic arenaviruses inhibit RIG-i-like receptor-dependent interferon production. $J$ Virol. (2015) 89:2944-55. doi: 10.1128/JVI.03349-14

275. Zhao J, Zeng Y, Xu S, Chen J, Shen G, Yu C, et al. A viral deamidase targets the helicase domain of RIG-I to block RNA-induced activation. Cell Host Microbe. (2016) 20:770-84. doi: 10.1016/j.chom.2016. 10.011

276. Li W, Chen H, Sutton T, Obadan A, Perez DR. Interactions between the Influenza A virus RNA polymerase components and retinoic acid-inducible gene I. J Virol. (2014) 88:10432-47. doi: 10.1128/JVI. 01383-14

277. Reynard S, Russier M, Fizet A, Carnec X, Baize S. Exonuclease domain of the Lassa virus nucleoprotein is critical to avoid RIG-I signaling and to inhibit the innate immune response. J Virol. (2014) 88:139237. doi: 10.1128/JVI.01923-14

278. Shao J, Huang Q, Liu X, Di D, Liang Y, Ly H. Arenaviral nucleoproteins suppress PACT-induced augmentation of RIG-I function to inhibit type I interferon production. J Virol. (2018) 5:ofy277. doi: 10.1128/JVI.00 $482-18$
279. Qin L, Ren L, Zhou Z, Lei X, Chen L, Xue Q, et al. Rotavirus non-structural protein 1 antagonizes innate immune response by interacting with retinoic acid inducible gene I. Virol J. (2011) 8:526. doi: 10.1186/1743-422X-8-526

280. Motz C, Schuhmann KM, Kirchhofer A, Moldt M, Witte G, Conzelmann $\mathrm{K}-\mathrm{K}$, et al. Paramyxovirus $\mathrm{V}$ proteins disrupt the fold of the RNA sensor MDA5 to inhibit antiviral signaling. Science. (2013) 339:6903. doi: 10.1126/science. 1230949

281. Sánchez-Aparicio MT, Feinman LJ, García-Sastre A, Shaw ML. Paramyxovirus $\mathrm{V}$ proteins interact with the RIG-I/TRIM25 regulatory complex and inhibit RIG-I signaling. J Virol. (2018) 92:e01960-17. doi: 10.1128/JVI.01960-17

282. Xing J, Wang S, Lin R, Mossman KL, Zheng C. Herpes simplex virus 1 tegument protein US11 downmodulates the RLR signaling pathway via direct interaction with RIG-I and MDA-5. $J$ Virol. (2012) 86:352840. doi: 10.1128/JVI.06713-11

283. Liu Y, Olagnier D, Lin R. Host and viral modulation of RIG-I-mediated antiviral immunity. Front Immunol. (2017) 7:662. doi: 10.3389/fimmu.2016.00662

284. Cui J, Song Y, Li Y, Zhu Q, Tan P, Qin Y, et al. USP3 inhibits type I interferon signaling by deubiquitinating RIG-I-like receptors. Cell Res. (2014) 24:40016. doi: $10.1038 /$ cr.2013.170

285. Li H, Zhao Z, Ling J, Pan L, Zhao X, Zhu H, et al. USP14 promotes K63linked RIG-I deubiquitination and suppresses antiviral immune responses. Eur J Immunol. (2018) 49:42-53. doi: 10.1002/eji.201847603

286. Jiang J, Tang H. Mechanism of inhibiting type I interferon induction by hepatitis B virus X protein. Protein Cell. (2010) 1:1106-17. doi: 10.1007/s13238-010-0141-8

287. Likai J, Shasha L, Wenxian Z, Jingjiao M, Jianhe S, Hengan W, et al. Porcine deltacoronavirus nucleocapsid protein suppressed IFN- $\beta$ production by interfering porcine RIG-I dsRNA-binding and K63-linked polyubiquitination. Front Immunol. (2019) 10:1024. doi: 10.3389/fimmu.2019.01024

288. Nguyen NTH, Now H, Kim W-J, Kim N, Yoo J-Y. Ubiquitin-like modifier FAT10 attenuates RIG-I mediated antiviral signaling by segregating activated RIG-I from its signaling platform. Sci Rep. (2016) 6:23377. doi: 10.1038/srep23377

289. Jiang J, Li J, Fan W, Zheng W, Yu M, Chen C, et al. Robust Lys63-linked ubiquitination of RIG-I promotes cytokine eruption in early influenza B virus infection. J Virol. (2016) 90:6263-75. doi: 10.1128/JVI.00549-16

290. Zhu J, Zhang Y, Ghosh A, Cuevas RA, Forero A, Dhar J, et al. Antiviral activity of human OASL protein is mediated by enhancing signaling of the RIG-I RNA sensor. Immunity. (2014) 40:936-48. doi: 10.1016/j.immuni.2014.05.007

291. Arimoto K, Takahashi H, Hishiki T, Konishi H, Fujita T, Shimotohno K. Negative regulation of the RIG-I signaling by the ubiquitin ligase RNF125. Proc Natl Acad Sci USA. (2007) 104:7500-5. doi: 10.1073/PNAS.0611551104

292. Chen W, Han C, Xie B, Hu X, Yu Q, Shi L, et al. Induction of Siglec-G by RNA viruses inhibits the innate immune response by promoting RIG-I degradation. Cell. (2013) 152:467-78. doi: 10.1016/j.cell.2013.01.011

293. Zhao K, Zhang Q, Li X, Zhao D, Liu Y, Shen Q, et al. Cytoplasmic STAT4 promotes antiviral type I IFN production by blocking CHIPmediated degradation of RIG-I kai. J Immunol. (2016) 196:120917. doi: 10.4049/jimmunol.1501224

294. Du Y, Duan T, Feng Y, Liu Q, Lin M, Cui J, et al. LRRC25 inhibits type I IFN signaling by targeting ISG15-associated RIG-I for autophagic degradation. EMBO J. (2018) 37:351-66. doi: 10.15252/embj.201796781

295. Xian H, Yang S, Jin S, Zhang Y, Cui J. LRRC59 modulates type I interferon signaling by restraining the SQSTM1/p62-mediated autophagic degradation of pattern recognition receptor DDX58/RIG-I. Autophagy. (2019). doi: 10.1080/15548627.2019.1615303. [Epub ahead of print].

296. Xia M, Gonzalez P, Li C, Meng G, Jiang A, Wang H, et al. Mitophagy enhances oncolytic measles virus replication by mitigating DDX58/RIG-Ilike receptor signaling. J Virol. (2014) 88:5152-64. doi: 10.1128/JVI.03851-13

297. Barral PM, Sarkar D, Fisher PB, Racaniello VR. RIG-I is cleaved during picornavirus infection. Virology. (2009) 391:1716. doi: 10.1016/J.VIROL.2009.06.045

298. Zhu Z, Wang G, Yang F, Cao W, Mao R, Du X, et al. Foot-andmouth disease virus viroporin $2 \mathrm{~B}$ antagonizes RIG-I-mediated antiviral 
effects by inhibition of its protein expression. J Virol. (2016) 90:1110621. doi: 10.1128/JVI.01310-16

299. Barral PM, Morrison JM, Drahos J, Gupta P, Sarkar D, Fisher PB, et al. MDA-5 is cleaved in poliovirus-infected cells. J Virol. (2007) 81:367784. doi: 10.1128/JVI.01360-06

300. Wang W, Jiang M, Liu S, Zhang S, Liu W, Ma Y, et al. RNF122 suppresses antiviral type I interferon production by targeting RIG-I CARDs to mediate RIG-I degradation. Proc Natl Acad Sci USA. (2016) 113:95816. doi: $10.1073 /$ pnas. 1604277113

301. Zhou P, Ding X, Wan X, Liu L, Yuan X, Zhang W, et al. MLL5 suppresses antiviral innate immune response by facilitating STUB1-mediated RIG-I degradation. Nat Commun. (2018) 9:1243. doi: 10.1038/s41467-018-03563-8

302. Matsumiya $T$, Imaizumi $T$, Yoshida $H$, Satoh $K$, Topham MK, Stafforini DM. The levels of retinoic acid-inducible gene I are regulated by heat shock protein 90-alpha. J Immunol. (2009) 182:2717-25. doi: 10.4049/jimmunol.0802933

303. Iwamura T, Yoneyama M, Koizumi N, Okabe Y, Namiki H, Samuel CE, et al. PACT, a double-stranded RNA binding protein acts as a positive regulator for type I interferon gene induced by Newcastle disease virus. Biochem Biophys Res Commun. (2001) 282:515-23. doi: 10.1006/BBRC.2001.4606

304. Kok K-HH, Lui P-YY, Ng M-HJHJ, Siu K-LL, Au SWN, Jin D-YY. The double-stranded RNA-binding protein PACT functions as a cellular activator of RIG-I to facilitate innate antiviral response. Cell Host Microbe. (2011) 9:299-309. doi: 10.1016/J.CHOM.2011.03.007

305. Chen K-R, Chang C-H, Huang C-Y, Lin C-Y, Lin W-Y, Lo Y-C, et al. TBK1associated protein in endolysosomes (TAPE)/CC2D1A is a key regulator linking RIG-I-like receptors to antiviral immunity. J Biol Chem. (2012) 287:32216-21. doi: 10.1074/jbc.C112.394346

306. Suzuki T, Oshiumi H, Miyashita M, Aly HH, Matsumoto M, Seya T. Cell type-specific subcellular localization of phosphoTBK1 in response to cytoplasmic viral DNA. PLoS ONE. (2013) 8:e83639. doi: 10.1371/journal.pone.0083639

307. Onorati M, Li Z, Liu F, Sousa AMM, Nakagawa N, Li M, et al. Zika virus disrupts phospho-TBK1 localization and mitosis in human neuroepithelial stem cells and radial glia. Cell Rep. (2016) 16:257692. doi: 10.1016/j.celrep.2016.08.038

308. Li S, Lu L-F, Li Z-C, Zhang C, Zhou X-Y, Zhou Y, et al. Zebrafish MVP recruits and degrades TBK1 to suppress IFN production. J Immunol. (2018) 202:559-66. doi: 10.4049/jimmunol.1801325

309. Outlioua A, Pourcelot M, Arnoult D. The role of optineurin in antiviral type I interferon production. Front Immunol. (2018) 9:853. doi: 10.3389/fimmu.2018.00853

310. Ibsen MS, Gad HH, Andersen LL, Hornung V, Julkunen I, Sarkar SN, et al. Structural and functional analysis reveals that human OASL binds dsRNA to enhance RIG-I signaling. Nucleic Acids Res. (2015) 43:523648. doi: $10.1093 / \mathrm{nar} / \mathrm{gkv} 389$

311. Beattie E, Denzler KL, Tartaglia J, Perkus ME, Paoletti E, Jacobs BL. Reversal of the interferon-sensitive phenotype of a vaccinia virus lacking E3L by expression of the reovirus S4 gene. J Virol. (1995) 69: 499-505.

312. Kok KH, Ng M-HJ, Ching Y-P, Jin D-Y. Human TRBP and PACT directly interact with each other and associate with dicer to facilitate the production of small interfering RNA. J Biol Chem. (2007) 282:1764957. doi: $10.1074 /$ jbc.M611768200

313. Schlee M, Hartmann E, Coch C, Wimmenauer V, Janke M, Barchet W, et al. Approaching the RNA ligand for RIG-I? Immunol Rev. (2009) 227:6674. doi: 10.1111/j.1600-065X.2008.00724.x

314. Brisse $\mathrm{M}$, Ly $\mathrm{H}$, Brisse $\mathrm{M}$, Ly $\mathrm{H}$. Viral inhibitions of PACT-induced RIG-I activation. Oncotarget. (2017) 5: 60725-6. doi: 10.18632/oncotarget. 18928

315. Brisse ME, Ly H. Hemorrhagic fever-causing arenaviruses: lethal pathogens and potent immune suppressors. Front Immunol. (2019) 10:372. doi: $10.3389 /$ fimmu.2019.00372

316. Chen J, Fang P, Wang M, Peng Q, Ren J, Wang D, et al. Porcine deltacoronavirus nucleocapsid protein antagonizes IFN- $\beta$ production by impairing dsRNA and PACT binding to RIG-I. Virus Genes. (2019). doi: 10.1007/s11262-019-01673-z. [Epub ahead of print].
317. Chen H, Li Y, Zhang J, Ran Y, Wei J, Yang Y, et al. RAVER1 is a coactivator of MDA5-mediated cellular antiviral response. J Mol Cell Biol. (2013) 5:1119. doi: $10.1093 / \mathrm{jmcb} / \mathrm{mjt} 006$

318. Yang Q, Bai S-Y, Li L-F, Li S, Zhang Y, Munir M, et al. Human hemoglobin subunit beta functions as a pleiotropic regulator of the RIGI/MDA5-mediated antiviral innate immune responses. J Virol. (2019). doi: 10.1128/JVI.00718-19. [Epub ahead of print].

319. Patel RC, Sen GC. PACT, a protein activator of the interferoninduced protein kinase, PKR. EMBO J. (1998) 17:437990. doi: 10.1093/emboj/17.15.4379

320. Marques JT, White CL, Peters GA, Williams BRG, Sen GC. The role of PACT in mediating gene induction, PKR activation, and apoptosis in response to diverse stimuli. J Interferon Cytokine Res. (2008) 28:46976. doi: $10.1089 /$ jir.2007.0006

321. Yoo J-S, Takahasi K, Ng CS, Ouda R, Onomoto K, Yoneyama $\mathrm{M}$, et al. DHX36 enhances RIG-I signaling by facilitating PKRmediated antiviral stress granule formation. PLoS Pathog. (2014) 10:e1004012. doi: 10.1371/journal.ppat.1004012

322. Yoneyama M, Jogi M, Onomoto K. Regulation of antiviral innate immune signaling by stress-induced RNA granules. J Biochem. (2016) 159:mvv122. doi: $10.1093 / \mathrm{jb} / \mathrm{mvv} 122$

323. Onomoto K, Jogi M, Yoo J-S, Narita R, Morimoto S, Takemura A, et al. Critical role of an antiviral stress granule containing RIG-I and PKR in viral detection and innate immunity. PLOS ONE. (2012) 7:e43031. doi: 10.1371/journal.pone.0043031

324. Sánchez-Aparicio MT, Ayllón J, Leo-Macias A, Wolff T, García-Sastre A. Subcellular localizations of RIG-I, TRIM25, and MAVS complexes. J Virol. (2017) 91:e01155-16. doi: 10.1128/JVI.01155-16

325. Pham AM, Santa Maria FG, Lahiri T, Friedman E, Marié IJ, Levy DE. PKR transduces MDA5-dependent signals for type I IFN induction. PLoS Pathog. (2016) 12:e1005489. doi: 10.1371/journal.ppat.1005489

326. Li L-F, Yu J, Zhang Y, Yang Q, Li Y, Zhang L, et al. Interferon-inducible oligoadenylate synthetase-like protein acts as an antiviral effector against classical swine fever virus via the MDA5-mediated type I interferon-signaling pathway. J Virol. (2017) 91:e01514-16. doi: 10.1128/JVI.01514-16

327. Xu L, Xiao N, Liu F, Ren H, Gu J, Beutler BA. Inhibition of RIG-I and MDA5dependent antiviral response by gClqR at mitochondria. PNAS. (2009) 106:1530-5. doi: 10.1073/pnas.0811029106

328. Ling T, Li S-N, Weng G-X, Wang W, Li C, Cao L, et al. TARBP2 negatively regulates IFN- $\beta$ production and innate antiviral response by targeting MAVS. Mol Immunol. (2018) 104:1-10. doi: 10.1016/J.MOLIMM.2018.10.017

329. Zhang W, Wang G, Xu Z-G, Tu H, Hu F, Dai J, et al. Lactate is a natural suppressor of RLR signaling by targeting MAVS. Cell. (2019) 178:176189.e15. doi: 10.1016/j.cell.2019.05.003

330. Cui J, Zhu L, Xia X, Wang HY, Legras X, Hong J, et al. NLRC5 negatively regulates the NF-kappaB and type I interferon signaling pathways. Cell. (2010) 141:483-96. doi: 10.1016/j.cell.2010.03.040

331. Pattabhi S, Knoll ML, Gale M, Loo Y-M. DHX15 is a coreceptor for RLR signaling that promotes antiviral defense against RNA virus infection. J Interf Cytokine Res. (2019) 39:331-46. doi: 10.1089/jir.2018.0163

332. Yang Y-K, Qu H, Gao D, Di W, Chen H-W, Guo X, et al. ARFlike protein 16 (ARL16) inhibits RIG-I by binding with its C-terminal domain in a GTP-dependent manner. J Biol Chem. (2011) 286:1056880. doi: $10.1074 /$ jbc.M110.206896

333. Kitai Y, Takeuchi O, Kawasaki T, Ori D, Sueyoshi T, Murase M, et al. Negative regulation of melanoma differentiation-associated gene 5 (MDA5)dependent antiviral innate immune responses by Arf-like protein 5B. J Biol Chem. (2015) 290:1269-80. doi: 10.1074/jbc.M114.611053

334. Ranjith-Kumar CT, Lai Y, Sarisky RT, Kao CC. Green tea catechin, epigallocatechin gallate, suppresses signaling by the dsRNA innate immune receptor RIG-I. PLoS ONE. (2010) 5:1-11. doi: 10.1371/journal.pone.0012878

335. Story RM, Li H, Abelson JN. Crystal structure of a DEAD box protein from the hyperthermophile Methanococcus jannaschii. Proc Natl Acad Sci USA. (2001) 98:1465-70. doi: 10.1073/pnas.98.4.1465

336. Heung LJ, Del Poeta M. Unlocking the DEAD-box: a key to cryptococcal virulence? J Clin Invest. (2005) 115:593-5. doi: 10.1172/JCI24508 
337. Poynter S, Lisser G, Monjo A, DeWitte-Orr S, Poynter S, Lisser G, et al. Sensors of infection: viral nucleic acid PRRs in fish. Biology. (2015) 4:46093. doi: 10.3390/biology4030460

338. Barber MRW, Aldridge JR, Webster RG, Magor KE, Magor KE. Association of RIG-I with innate immunity of ducks to influenza. Proc Natl Acad Sci USA. (2010) 107:5913-8. doi: 10.1073/pnas.1001755107

339. Rajendran KV, Zhang J, Liu S, Peatman E, Kucuktas H, Wang $\mathrm{X}$, et al. Pathogen recognition receptors in channel catfish: II. Identification, phylogeny and expression of retinoic acid-inducible gene I (RIG-I)-like receptors (RLRs). Dev Comp Immunol. (2012) 37:381-9. doi: 10.1016/J.DCI.2012.02.004

340. Sun Y, Ding N, Ding SS, Yu S, Meng C, Chen H, et al. Goose RIG-I functions in innate immunity against Newcastle disease virus infections. Mol Immunol. (2013) 53:321-7. doi: 10.1016/J.MOLIMM.2012.08.022

341. Aoki T, Hikima J, Hwang SD, Jung TS. Innate immunity of finfish: primordial conservation and function of viral RNA sensors in teleosts. Fish Shellfish Immunol. (2013) 35:1689-702. doi: 10.1016/J.FSI.2013.02.005

342. He Y, Pan H, Zhang G, He S. Comparative study on pattern recognition receptors in non-teleost ray-finned fishes and their evolutionary significance in primitive vertebrates. Sci China Life Sci. (2019) 62:566-78. doi: 10.1007/s11427-019-9481-8

343. Chen J, Shang S, Wu X, Zhong H, Zhao C, Wei Q, et al. Genomic analysis and adaptive evolution of the RIG-I-like and NOD-like receptors in reptiles. Int J Biol Macromol. (2019) 134:1045-51. doi: 10.1016/J.IJBIOMAC.2019.05.172

344. Inohara $\mathrm{N}$, Chamaillard $\mathrm{M}$, McDonald $\mathrm{C}$, Nuñez G. NODLRR PROTEINS: role in host-microbial interactions and inflammatory disease. Annu Rev Biochem. (2005) 74:35583. doi: 10.1146/annurev.biochem.74.082803.133347

345. Kersse K, Vanden Berghe T, Lamkanfi M, Vandenabeele P. A phylogenetic and functional overview of inflammatory caspases and caspase-1-related CARD-only proteins. Biochem Soc Trans. (2007) 35:1508-11. doi: 10.1042/BST0351508

346. Kufer TA, Fritz JH, Philpott DJ. NACHT-LRR proteins (NLRs) in bacterial infection and immunity. Trends Microbiol. (2005) 13:3818. doi: 10.1016/j.tim.2005.06.004

347. Chiu J, DeSalle R, Lam HM, Meisel L, Coruzzi G. Molecular evolution of glutamate receptors: a primitive signaling mechanism that existed before plants and animals diverged. Mol Biol Evol. (1999) 16:82638. doi: 10.1093/oxfordjournals.molbev.a026167

348. Leszczyniecka M, DeSalle R, Kang D, Fisher PB. The origin of polynucleotide phosphorylase domains. Mol Phylogenet Evol. (2004) 31:12330. doi: 10.1016/J.YMPEV.2003.07.012

349. Cagliani R, Forni D, Tresoldi C, Pozzoli U, Filippi G, Rainone $\mathrm{V}$, et al. RIG-I-like receptors evolved adaptively in mammals, with parallel evolution at LGP2 and RIG-I. J Mol Biol. (2014) 426:135165. doi: 10.1016/j.jmb.2013.10.040

350. Li N, Li A, Zheng K, Liu X, Gao L, Liu D, et al. Identification and characterization of an atypical RIG-I encoded by planarian Dugesia japonica and its essential role in the immune response. Dev Comp Immunol. (2019) 91:72-84. doi: 10.1016/J.DCI.2018.10.007

351. Coffman SR, Lu J, Guo X, Zhong J, Jiang H, Broitman-Maduro G, et al. Caenorhabditis elegans RIG-I homolog mediates antiviral RNA interference downstream of dicer-dependent biogenesis of viral small interfering RNAs. MBio. (2017) 8:e00264-17. doi: 10.1128/mBio.00264-17

352. Wang P-H, Weng S-P, He J-G. Nucleic acid-induced antiviral immunity in invertebrates: an evolutionary perspective. Dev Comp Immunol. (2015) 48:291-6. doi: 10.1016/J.DCI.2014.03.013

353. Eyk CL, Samaraweera SE, Scott A, Webber DL, Harvey DP, Mecinger O, et al. 'Non-self' mutation: double-stranded RNA elicits antiviral pathogenic response in a Drosophila model of expanded CAG repeat neurodegenerative diseases. Hum Mol Genet. (2019). doi: 10.1093/hmg/ddz096. [Epub ahead of print].

354. Zipfel C. Plant pattern-recognition receptors. Trends Immunol. (2014) 35:345-51. doi: 10.1016/j.it.2014.05.004

355. Incarbone $M$, Dunoyer P. RNA silencing and its suppression: novel insights from in planta analyses. Trends Plant Sci. (2013) 18:38292. doi: 10.1016/j.tplants.2013.04.001
356. Kørner CJ, Klauser D, Niehl A, Domínguez-Ferreras A, Chinchilla D, Boller $\mathrm{T}$, et al. The immunity regulator BAK1 contributes to resistance against diverse RNA viruses. Mol Plant-Microbe Interact. (2013) 26:127180. doi: 10.1094/MPMI-06-13-0179-R

357. Gong X-Y, Zhang Q-M, Gui J-F, Zhang Y-B. SVCV infection triggers fish IFN response through RLR signaling pathway. Fish Shellfish Immunol. (2019) 86:1058-63. doi: 10.1016/J.FSI.2018.12.063

358. Zhang Q-M, Zhao X, Li Z, Wu M, Gui J-F, Zhang Y-B. Alternative splicing transcripts of zebrafish LGP2 gene differentially contribute to IFN antiviral response. J Immunol. (2018) 200:688-703. doi: 10.4049/jimmunol. 1701388

359. Xu T, Chu Q, Cui J, Bi D. Inducible MicroRNA-3570 feedback inhibits the RIG-I-dependent innate immune response to rhabdovirus in teleost fish by targeting MAVS/IPS-1. J Virol. (2018) 92:e0159417. doi: 10.1128/JVI.01594-17

360. Sun Y, Han J, Chu Q, Liu X, Xu T. microRNA-210 participates in regulating RIG-I signaling pathway via targeting DUBA in miiuy croaker after poly(I:C) stimulation. Fish Shellfish Immunol. (2018) 77:17. doi: 10.1016/J.FSI.2018.02.003

361. Gu T, Lu L, An C, Chen B, Wei W, Wu X, et al. MDA5 and LGP2 acts as a key regulator though activating NF-кB and IRF3 in RLRs signaling of mandarinfish. Fish Shellfish Immunol. (2019) 86:111422. doi: 10.1016/J.FSI.2018.12.054

362. Zou PF, Chang MX, Li Y, Huan Zhang S, Fu JP, Chen SN, et al. Higher antiviral response of RIG-I through enhancing RIG-I/MAVS-mediated signaling by its long insertion variant in zebrafish. Fish Shellfish Immunol. (2015) 43:13-24. doi: 10.1016/J.FSI.2014.12.001

363. Gack MU, Kirchhofer A, Shin YC, Inn K-S, Liang C, Cui S, et al. Roles of RIG-I N-terminal tandem CARD and splice variant in TRIM25-mediated antiviral signal transduction. Proc Natl Acad Sci USA. (2008) 105:167438. doi: 10.1073/pnas.0804947105

364. Miranzo-Navarro D, Magor KE. Activation of duck RIG-I by TRIM25 is independent of anchored ubiquitin. PLoS ONE. (2014) 9:e86968. doi: 10.1371/journal.pone.0086968

365. Helin AS, Wille M, Atterby C, Järhult J, Waldenström J, Chapman JR. Expression of immune genes RIG-I and $\mathrm{Mx}$ in mallard ducks infected with low pathogenic avian influenza (LPAI): a dataset. Data Br. (2018) 18:1562-6. doi: 10.1016/j.dib.2018.04.061

366. Huo H, Wang Y, Wang D, Wang Y, Chen X, Zhao L, et al. Duck RIGI restricts duck enteritis virus infection. Vet Microbiol. (2019) 230:7885. doi: 10.1016/J.VETMIC.2019.01.014

367. Sun $\mathrm{X}$, Li W, Liu E, Huang $\mathrm{H}$, Wang $\mathrm{T}$, Wang $\mathrm{X}$, et al. In vivo cellular and molecular study on duck spleen infected by duck Tembusu virus. Vet Microbiol. (2019) 230:32-44. doi: 10.1016/J.VETMIC.2018.12.003

368. Wei LM, Jiao PR, Song YF, Han F, Cao L, Yang F, et al. Identification and expression profiling analysis of goose melanoma differentiation associated gene 5 (MDA5) gene. Poult Sci. (2013) 92:2618-24. doi: 10.3382/ps.2013-03064

369. Sun Y, Mao X, Zheng H, Wu W, Rehman ZU, Liao Y, et al. Goose MAVS functions in RIG-I-mediated IFN- $\beta$ signaling activation. Dev Comp Immunol. (2019) 93:58-65. doi: 10.1016/J.DCI.2018.12.006

370. Karpala AJ, Stewart C, McKay J, Lowenthal JW, Bean AGD. Characterization of chicken Mda5 activity: regulation of IFN$\beta$ in the absence of RIG-I functionality. J Immunol. (2011) 186:5397-405. doi: 10.4049/jimmunol.1003712

371. Liniger M, Summerfield A, Zimmer G, McCullough KC, Ruggli N. Chicken cells sense influenza A virus infection through MDA5 and CARDIF signaling involving LGP2. J Virol. (2012) 86:705. doi: 10.1128/JVI. 00742-11

372. Hayashi T, Watanabe C, Suzuki Y, Tanikawa T, Uchida Y, Saito T. Chicken MDA5 senses short double-stranded RNA with implications for antiviral response against avian influenza viruses in chicken. J Innate Immun. (2014) 6:58-71. doi: 10.1159/000351583

373. Li G-Q, Tian Y, Chen L, Shen J-D, Tao Z-R, Zeng T, et al. Cloning, expression and bioinformatics analysis of a putative pigeon melanoma differentiation-associated gene 5. Br Poult Sci. (2018) 60:94-104. doi: 10.1080/00071668.2018.1564241 
374. Xu L, Yu D, Fan Y, Peng L, Wu Y, Yao Y-G. Loss of RIG-I leads to a functional replacement with MDA5 in the Chinese tree shrew. Proc Natl Acad Sci USA. (2016) 113:10950-5. doi: 10.1073/pnas.1604939113

375. Wei Y, Zhou H, Wang A, Sun L, Wang M, Jia R, et al. TRIM25 identification in the Chinese goose: gene structure, tissue expression profiles, and antiviral immune responses in vivo and in vitro. Biomed Res Int. (2016) 2016:1403984. doi: 10.1155/2016/1403984

376. Chang M, Collet B, Nie P, Lester K, Campbell S, Secombes CJ, et al. Expression and functional characterization of the RIG-I-like receptors MDA5 and LGP2 in Rainbow trout (Oncorhynchus mykiss). J Virol. (2011) 85:8403-12. doi: 10.1128/JVI.00445-10

377. Weber M, Sediri H, Felgenhauer U, Binzen I, Bänfer S, Jacob R, et al. Influenza virus adaptation PB2-627K modulates nucleocapsid inhibition by the pathogen sensor RIG-I. Cell Host Microbe. (2015) 17:30919. doi: 10.1016/J.CHOM.2015.01.005

378. Ariumi Y. Multiple functions of DDX3 RNA helicase in gene regulation, tumorigenesis, and viral infection. Front Genet. (2014) 5:423. doi: 10.3389/fgene.2014.00423

379. Valiente-Echeverría F, Hermoso MA, Soto-Rifo R. RNA helicase DDX3: at the crossroad of viral replication and antiviral immunity. Rev Med Virol. (2015) 25:286-99. doi: 10.1002/rmv.1845

380. Gringhuis SI, Hertoghs N, Kaptein TM, Zijlstra-Willems EM, SarramiFooroshani R, Sprokholt JK, et al. HIV-1 blocks the signaling adaptor MAVS to evade antiviral host defense after sensing of abortive HIV-1 RNA by the host helicase DDX3. Nat Immunol. (2016) 18:225-35. doi: 10.1038/ni.3647

381. Szappanos D, Tschismarov R, Perlot T, Westermayer S, Fischer $\mathrm{K}$, Platanitis E, et al. The RNA helicase DDX3X is an essential mediator of innate antimicrobial immunity. PLOS Pathog. (2018) 14:e1007397. doi: 10.1371/journal.ppat.1007397

382. Zhang Z, Yuan B, Lu N, Facchinetti V, Liu Y-J. DHX9 pairs with IPS-1 to sense double-stranded RNA in myeloid dendritic cells. J Immunol. (2011) 187:4501-8. doi: 10.4049/jimmunol.1101307

383. Lu H, Lu N, Weng L, Yuan B, Liu Y-J, Zhang Z. DHX15 senses doublestranded RNA in myeloid dendritic cells. J Immunol. (2014) 193:136472. doi: 10.4049/jimmunol.1303322

384. Zhang Z, Kim T, Bao M, Facchinetti V, Jung SY, Ghaffari AA, et al. DDX1, DDX21, and DHX36 helicases form a complex with the adaptor molecule TRIF to sense dsRNA in dendritic cells. Immunity. (2011) 34:86678. doi: 10.1016/j.immuni.2011.03.027

385. Liu Y, Lu N, Yuan B, Weng L, Wang F, Liu Y-J, et al. The interaction between the helicase DHX33 and IPS-1 as a novel pathway to sense double-stranded RNA and RNA viruses in myeloid dendritic cells. Cell Mol Immunol. (2014) 11:49-57. doi: 10.1038/cmi.2013.40

386. Zhang K, Zhang Y, Xue J, Meng Q, Liu H, Bi C, et al. DDX19 inhibits type I interferon production by disrupting TBK1-IKKE-IRF3 interactions and promoting TBK1 and IKKE degradation. Cell Rep. (2019) 26:125872.e4. doi: 10.1016/j.celrep.2019.01.029

387. Loureiro ME, Zorzetto-Fernandes AL, Radoshitzky S, Chi X, Dallari $\mathrm{S}$, Marooki N, et al. DDX3 suppresses type I interferons and favors viral replication during Arenavirus infection. PLOS Pathog. (2018) 14:e1007125. doi: 10.1371/journal.ppat.1007125

388. Park E, Byun YH, Park S, Jang YH, Han W, Won J, et al. Codegradation of interferon signaling factor DDX3 by PB1-F2 as a basis for high virulence of 1918 pandemic influenza. EMBO J. (2019) 38:e99475. doi: 10.15252/embj.201899475

389. Mosallanejad K, Sekine Y, Ishikura-Kinoshita S, Kumagai K, Nagano T, Matsuzawa A, et al. The DEAH-box RNA helicase DHX15 activates NF-кB and MAPK signaling downstream of MAVS during antiviral responses. Sci Signal. (2014) 7:ra40. doi: 10.1126/scisignal.2004841

390. Miyashita M, Oshiumi H, Matsumoto M, Seya T. DDX60, a DEXD/H box helicase, is a novel antiviral factor promoting RIG-I-like receptor-mediated signaling. Mol Cell Biol. (2011) 31:3802-19. doi: 10.1128/MCB.01368-10

391. Oshiumi H, Miyashita M, Okamoto M, Morioka Y, Okabe M, Matsumoto $\mathrm{M}$, et al. DDX60 is involved in RIG-I-dependent and independent antiviral responses, and its function is attenuated by virus-induced EGFR activation. Cell Rep. (2015) 11:1193-207. doi: 10.1016/j.celrep.2015.04.047

392. Zhu Q, Tan P, Li Y, Lin M, Li C, Mao J, et al. DHX29 functions as an RNA cosensor for MDA5-mediated EMCV-specific antiviral immunity. PLoS Pathog. (2018) 14:e1006886. doi: 10.1371/journal.ppat.1006886

393. Elion DL, Cook RS. Activation of RIG-I signaling to increase the pro-inflammatory phenotype of a tumor. Oncotarget. (2019) 10:23389. doi: 10.18632/oncotarget.26729

394. Aznar MA, Planelles L, Perez-Olivares M, Molina C, Garasa S, Etxeberría I, et al. Immunotherapeutic effects of intratumoral nanoplexed poly I:C. $J$ Immunother Cancer. (2019) 7:116. doi: 10.1186/s40425-019-0568-2

395. Yong HY, Luo D. RIG-I-like receptors as novel targets for panantivirals and vaccine adjuvants against emerging and re-emerging viral infections. Front Immunol. (2018) 9:1379. doi: 10.3389/fimmu.2018. 01379

Conflict of Interest Statement: The authors declare that the research was conducted in the absence of any commercial or financial relationships that could be construed as a potential conflict of interest.

Copyright (c) 2019 Brisse and Ly. This is an open-access article distributed under the terms of the Creative Commons Attribution License (CC BY). The use, distribution or reproduction in other forums is permitted, provided the original author(s) and the copyright owner(s) are credited and that the original publication in this journal is cited, in accordance with accepted academic practice. No use, distribution or reproduction is permitted which does not comply with these terms. 